\title{
Curve momentum
}

Article

Accepted Version

Creative Commons: Attribution-Noncommercial-No Derivative Works 4.0

Paschke, R., Prokopczuk, M. and Wese Simen, C. (2020) Curve momentum. Journal of Banking \& Finance, 113. 105718. ISSN 0378-4266 doi: https://doi.org/10.1016/j.jbankfin.2019.105718 Available at https://centaur.reading.ac.uk/87795/

It is advisable to refer to the publisher's version if you intend to cite from the work. See Guidance on citing.

To link to this article DOI: http://dx.doi.org/10.1016/j.jbankfin.2019.105718

Publisher: Elsevier

All outputs in CentAUR are protected by Intellectual Property Rights law, including copyright law. Copyright and IPR is retained by the creators or other copyright holders. Terms and conditions for use of this material are defined in the End User Agreement.

\section{$\underline{\text { www.reading.ac.uk/centaur }}$}

\section{CentAUR}

Central Archive at the University of Reading

Reading's research outputs online 
Journal Pre-proof

Curve Momentum

Raphael Paschke, Marcel Prokopczuk, Chardin Wese Simen

PII: S0378-4266(19)30291-2

DOI: https://doi.org/10.1016/j.jbankfin.2019.105718

Reference: JBF 105718

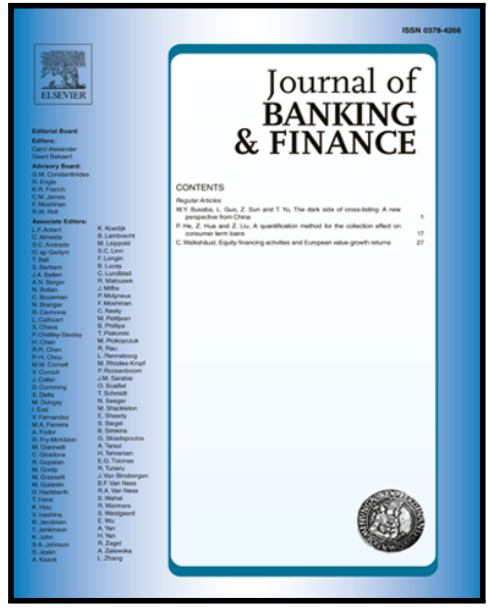

To appear in:

Journal of Banking and Finance

Received date: $\quad 15$ April 2018

Accepted date: $\quad 23$ November 2019

Please cite this article as: Raphael Paschke, Marcel Prokopczuk, Chardin Wese Simen, Curve Momentum, Journal of Banking and Finance (2019), doi: https://doi.org/10.1016/j.jbankfin.2019.105718

This is a PDF file of an article that has undergone enhancements after acceptance, such as the addition of a cover page and metadata, and formatting for readability, but it is not yet the definitive version of record. This version will undergo additional copyediting, typesetting and review before it is published in its final form, but we are providing this version to give early visibility of the article. Please note that, during the production process, errors may be discovered which could affect the content, and all legal disclaimers that apply to the journal pertain.

(C) 2019 Published by Elsevier B.V. 


\title{
Curve Momentum*
}

\author{
Raphael Paschke ${ }^{\dagger}$, Marcel Prokopczuk ${ }^{\ddagger}, \S$ and Chardin Wese Simen $\mathbb{I}$
}

\begin{abstract}
We propose a momentum strategy that operates within commodity futures curves. The diversified curve momentum strategy generates a significantly positive average excess return and a (annualized) Sharpe ratio of 1.28 . The profitability of the strategy has increased markedly in the more recent years. These excess returns are difficult to reconcile with risk based explanations, as evidenced by the significantly positive alpha after controlling for exposure to several well-known risk factors. The average excess return on the diversified curve momentum strategy remains significantly positive even after accounting for transaction costs.
\end{abstract}

\section{JEL classification: G12, G13}

Keywords: Behavioral, Commodities, Curve, Momentum, Term Structure

${ }^{*}$ We thank the anonymous reviewers, Devraj Basu, Robert Bianchi (Discussant), Chris Brooks, Charlie Cai, Chris Florackis, Fabian Hollstein, Joëlle Miffre, Maximillian Neumann, Ogonna Nneji, Sofia Ramos, Ludovico Rossi, Simon Rottke (Discussant), Xiao Qiao, Benoit Sevi, Oliver Schwindler, Marta Szymanowska, Paola Zerilli (Discussant) and seminar participants at the Commodity and Energy Markets Association (2017), the Commodity Markets Winter Workshop (2018), the German Finance Association (2018), the University of Reading (2018), the University of Liverpool (2018), and the Australasian Commodity Markets Conference (2019) for helpful comments and discussions.

${ }^{\dagger}$ Leibniz University Hannover, Koenigsworther Platz 1, D-30167 Hannover, Germany. Contact: r.paschke@web.de

$\stackrel{\ddagger}{\ddagger}$ Leibniz University Hannover, Koenigsworther Platz 1, D-30167 Hannover, Germany. Contact: prokopczuk@fmt.uni-hannover.de

§ICMA Centre, Henley Business School, University of Reading, Reading, RG6 6BA, United Kingdom.

IManagement School, University of Liverpool, Liverpool, L69 7ZH, United Kingdom. Contact: c.wesesimen@liverpool.ac.uk 


\section{Introduction}

In a seminal study, Jegadeesh and Titman (1993) document the profitability of the momentum strategy in equity markets. Recent studies, e.g. Miffre and Rallis (2007), Fuertes et al. (2010), Asness et al. (2013), and Gorton et al. (2013), extend this finding to commodity futures markets by documenting the profitability of the conventional momentum strategy. A common feature of these works is that they focus on the first nearby futures contract of different commodity futures markets. While this approach parallels the methodology of studies on the equity market, it does not exploit an important dimension of commodity futures markets: the term structure.

This observation motivates us to implement the momentum strategy within individual futures curves by trading different maturities of the same commodity. The curve momentum strategy involves long-short fully collateralized positions in the first 2 nearby contracts of each commodity futures curve. We measure the curve momentum signal using all excess return observations of the previous 12 months and open a long position in the nearby contract with the higher curve momentum signal and a short position in the other nearby. We then hold these positions for 1 month. The curve momentum strategy diversified across commodity sectors yields a significantly positive average excess return and a (annualized) Sharpe ratio $(S R)$ of 1.28 . These excess returns are positively skewed, thus posing a challenge to an explanation based on crash risk. Moreover, they survive transaction costs as evidenced by a $S R$ of 0.85 , after accounting for transaction costs, making it difficult to argue that the diversified curve momentum excess returns persist because of limits-to-arbitrage.

The diversified curve momentum strategy offers a better risk-return trade-off $(S R=$ 
1.28) than the conventional commodity momentum $(S R=0.72)$ and carry $(S R=0.60)$ strategies. Regressing its excess returns on a constant and those of well-known strategies, including the aforementioned conventional strategies, we find that the average risk-adjusted excess return remains significant and is very similar in magnitude to the raw average excess return. Furthermore, the diversified curve momentum strategy excess returns do not have a significant exposure to traditional macroeconomic variables such as the U.S. industrial production growth rate. These findings lead us to conclude that the performance of the diversified curve momentum strategy is difficult to reconcile with a risk based explanation.

Therefore, we turn our attention to the behavioral models of Daniel et al. (1998) and Hong and Stein (1999). We exploit the passing of the Commodity Futures Modernization Act (CFMA) in December 2000, which lowers the barrier to speculation (Boons et al., 2012), to distinguish between these two theories. The model of Daniel et al. (1998) predicts a substantially stronger curve momentum effect during the period following the CFMA. Consistent with this theory, we find that the average diversified curve momentum excess return increases significantly from the pre-CFMA period to the period following the CFMA.

We perform several additional tests to evaluate the robustness of the results. To begin with, we increase the number of investable nearby contracts from 2 in our benchmark specification to 6 nearbys and obtain qualitatively similar results. We also consider alternative formation and holding periods. We find that the diversified curve momentum strategy remains profitable for these alternative choices. Next, we test the hypothesis that the curve momentum strategy is merely a manifestation of the Samuelson effect (Samuelson, 1965) and find no empirical support for this hypothesis.

Our paper contributes to the broad literature on commodity risk premia. Erb and Harvey 
(2006), Miffre and Rallis (2007), Fuertes et al. (2010), Gorton et al. (2013) and Koijen et al. (2018), among others, document the profitability of the conventional momentum and carry strategies in commodity futures markets. Relative to these studies, we implement the momentum strategy within each commodity futures curve. Our research offers insights both from the methodological and practical standpoints. From a methodological perspective, the implementation of the momentum strategy within each commodity futures curve enables us to rule out explanations of the momentum effect that rely on differences, across commodity futures markets, along dimensions such as storage costs and harvesting/production cycles. From a practical perspective, the curve momentum strategy may be of interest to asset managers seeking to diversify away from conventional commodity trading strategies.

Our analysis relates to a growing body of research that analyses futures contracts of different maturities. De Groot et al. (2014) explore the question of how to optimally select the maturity of futures contracts used in the conventional momentum strategy. Boons and Prado (2019) introduce the basis momentum strategy, with the basis momentum being defined as the difference between momentum in the first and second nearby futures contracts. They open long positions in the first nearby contract of the futures markets with large basis momentum and short positions in the first nearby contract of markets with small basis momentum. Our work is different in that we analyze each futures curve in isolation and do not use information from the cross-section of futures curves to determine the trading signal as they do. We show that the diversified curve momentum strategy provides a significantly positive alpha after controlling for exposure to both the basis momentum and the hedged basis momentum strategies.

Our study also contributes to the growing literature that tests the predictions of the 
behavioral theories of momentum of Daniel et al. (1998) and Hong and Stein (1999). Chui et al. (2003) exploit an important shock to the real estate investment trust (REIT) market to distinguish between the theories. Ang et al. (2013) compare the momentum strategy implemented using the cross-section of stocks traded over-the-counter (OTC) to the momentum strategy implemented using exchange traded stocks. Goetzmann and Huang (2018) take a historical approach and exploit the features of stock market trading in imperial Russia to distinguish between the two theories. We complement this literature by exploiting a regulatory change in commodity futures markets to distinguish between these theories of momentum. The performance of the diversified curve momentum strategy appears to be mostly consistent with the behavioural model of Daniel et al. (1998).

This paper proceeds as follows. Section 2 presents the data and methodology. Section 3 discusses the main empirical results. Section 4 presents some additional results and robustness checks. Finally, Section 5 concludes.

\section{Data and Methodology}

\subsection{Data}

We obtain the commodity futures data from the Commodity Research Bureau (CRB). The sample period extends from January 1986 to February 2015. The data is available at the daily frequency and covers the following 22 commodity futures markets: Brent oil, West Texas Intermediate (WTI) oil, heating oil, natural gas, corn, oats, rice, wheat, cotton, lumber, live cattle, lean hogs, gold, copper, silver, soy oil, soybeans, soy meal, cocoa, or- 
ange, coffee and sugar. Together, these markets span 7 commodity sectors: energy, grains, industrials, meats, metals, oilseeds and softs.

Similar to Szymanowska et al. (2014), we roll the first nearby contract at the end of the second month before the last trading day. By adopting this rollover practice, we aim to avoid the erratic price behavior of futures contracts observed near expiration. It is worth pointing out that, by specifying a rollover practice for the first nearby, we essentially rollover the entire futures curve. To illustrate this, suppose that we rollover the first nearby contract at the end of day $t$. The futures contract that is viewed as the second nearby at the end of day $t$ becomes the first nearby on day $t+1$. Similarly, the futures contract that represents the third nearby at the end of day $t$ becomes the second nearby on day $t+1$. More generally, the futures contract that is the $n^{\text {th }}$ nearby at the end of day $t$ becomes the $(n-1)^{t h}$ nearby on day $t+1$.

The preceding discussion suggests that the time-series of a specific nearby is not necessarily based on the same futures contract. As a result, one needs to be cautious to avoid mixing information from different futures contracts when computing the excess returns on a nearby series. We therefore follow Singleton (2014) in our computation of the excess return series which ensures that each excess return is based on the same contract, and thus realizable. For ease of exposition, it is helpful to distinguish between two cases. The first relates to the situation where there was not a rollover at the end of the previous day, i.e. the futures contract that is currently considered as the $i^{\text {th }}$ nearby was also the $i^{\text {th }}$ nearby at the end of the previous day. In this case, we compute the excess return on the $i^{\text {th }}$ nearby by simply using the consecutive prices of the same nearby series. The second case focuses on the situation where there was a rollover at the end of the previous day. In this case, we 
compute the excess return on the $i^{\text {th }}$ nearby based on the ratio of the current price of that specific nearby over that of the $(i+1)^{t h}$ nearby observed at the end of the previous day. More formally, we compute the excess return on a fully collateralized position in each commodity futures (Koijen et al., 2018) as follows: ${ }^{1}$

$$
R_{t+1}^{(m, i)}= \begin{cases}\frac{F_{t+1}^{(m, i)}}{F_{t}^{(m, i)}}-1 & \text { If there is no rollover at the end of day } t \\ \frac{F_{t+1}^{(m, i)}}{F_{t}^{(m, i+1)}}-1 & \text { Otherwise }\end{cases}
$$

where $R_{t+1}^{(m, i)}$ denotes the simple excess return on the $i^{t h}$ nearby of the commodity futures market $m$ realized at $t+1 . F_{t+1}^{(m, i)}$ refers to the price of the $i^{t h}$ nearby at $t+1$. Finally, $F_{t}^{(m, i+1)}$ is the price of the $i+1^{t h}$ nearby of the commodity futures market $m$ at $t$.

Using the framework discussed above, we compute the time-series of daily excess returns for each nearby series of each commodity futures market. We then compound each of the daily excess return series to obtain the corresponding price indices. Finally, we use the resulting nearby price series to compute the excess returns at the horizon of interest (Moskowitz et al., 2012).

Table 1 provides an overview of the dataset. It lists all the markets that make up each commodity sector. The table also shows that the (annualized) mean and volatility of the

\footnotetext{
${ }^{1}$ While our computation of returns is consistent with the literature, e.g. Moskowitz et al. (2012), Singleton (2014) and Szymanowska et al. (2014), it is important to highlight that, in practice, a trader entering into a futures contract is required to pay the initial margin in the margin account. If the balance of the margin account drops below a certain level, known as the maintenance margin, the trader must top up the account to bring its balance back to the initial margin level. Hedegaard (2014) reports that the average maintenance margin in commodity futures markets ranges between $2 \%$ and $9.8 \%$ of the contract value. Furthermore, the author shows that, for most contracts analyzed, the maintenance margin represents $74.1 \%$ of the initial margin. These estimates are consistent with the information currently available from the exchange's website. See for instance https://institute.cmegroup.com/courses/introduction-to-futures-html/modules/ margin-know-what-is-needed. This remark is interesting for two reasons. First, it suggests that there is an important degree of leverage inherent to commodity futures. Second, computing the futures returns relative to the margin, instead of assuming a fully collateralized position, would have further enhanced the average returns we present throughout this paper (Miffre and Rallis, 2007).
} 
first two nearby excess returns of each commodity futures market are generally similar. Furthermore, it highlights a strong correlation between the nearby excess returns of each market. This conclusion is supported by correlation estimates that are greater than $93 \%$.

\subsection{Methodology}

Our primary objective is to analyze the performance of the curve momentum $C-M O M(12,1)$ strategy implemented within the futures curve of each commodity market. This strategy uses a measurement period of $12 \operatorname{month}(\mathrm{s})$ and a holding period of 1 month(s). ${ }^{2}$ To fix ideas, suppose we want to implement this strategy in a specific commodity futures market $m$. At the end of month $t$, we use all the price series data obseryed over the most recent 12 month(s), i.e. from the end of month $t-12$ to the end of month $t$ to measure the curve momentum signal. The time $t$ curve momentum trading signal related to the $i^{\text {th }}$ nearby of the commodity futures market $m\left(S_{C-M O M, t}^{(m, i)}\right)$ is computed as the simple excess return on that nearby over the measurement period. We denote by $N_{t}^{m}$ the number of nearbys of the commodity futures market $m$ for which we have price data over the measurement period. Next, we rank the $N_{t}^{m}$ nearbys in ascending order of their curve momentum signal. We then create a portfolio containing the top half of nearbys with a high signal and another portfolio comprising the bottom half of nearbys with a low signal. All nearbys are equal-weighted within each of the

\footnotetext{
${ }^{2}$ Our interest in a measurement period of 12 months is mainly motivated by the fact that some commodity markets, e.g. natural gas, are highly seasonal (Back et al., 2013; Diewald et al., 2015; Arismendi et al., 2016). By taking a measurement window of 12 months, we aim to mitigate the potential concern that our results may be affected by the seasonality of commodity markets. The choice of a holding period of 1 month is consistent with the literature on commodity futures risk premia, e.g. Szymanowska et al. (2014). As a robustness check, we consider alternative measurement and holding periods (see Section 4.2).
} 
two portfolios. ${ }^{3}$ We hold the constructed portfolio for 1 month and compute the realized excess return on the curve momentum strategy $\left(R_{C-M O M, t+1}^{(m)}\right)$ implemented in commodity futures market $m .{ }^{4}$ We implement the steps above for each calendar month and for each commodity futures curve separately. Thus, we obtain the time-series of curve momentum excess returns for each commodity futures market.

In the main analysis, we only consider investments in the first two nearbys of each commodity futures market, i.e. $N_{t}^{m}=2 .^{5}$ This choice is motivated by the observation that the majority of trading activity in commodity futures concentrates at the front-end of the curve (De Groot et al., 2014). By taking this step, we address the potential concern that the curve momentum strategy might involve thinly traded contracts. Additionally, this decision facilitates the implementation of the strategy since, for each commodity futures curve, the long and short legs of the strategy contain 1 contract each. Furthermore, by focusing only on the first two nearby contracts of each market, we can rule out the possibility that the performance of the curve momentum strategy is due to differences in inventory expectations or storage costs along the curve. This is because inventory conditions and storage costs are unlikely to be significantly different for the first two consecutive nearby contracts.

\footnotetext{
${ }^{3}$ The equal-weighting scheme is a popular approach in the literature on commodity futures risk premia (Miffre and Rallis, 2007; Fuertes et al., 2010). In a robustness check, we also implement the rank-weighting scheme of Koijen et al. (2018). This is an interesting analysis since the equal- and rank-weighted schemes are not the same if one trades more than 2 nearby contracts of each commodity futures market.

${ }^{4}$ Notice that this approach assumes that the investor observes the signal and directly implements the strategy. In practice, most companies face a decision delay. For instance, the decision to invest might rest with a board that could take some time to approve the strategy. Clearly, the strategy we present here does not account for the decision delay. Section 4.5 discusses the empirical implications of a plausible decision delay.

${ }^{5}$ As a robustness check, we consider as many as 6 nearby contracts for each commodity futures curve. Section 4.1 shows that extending the number of contracts does not materially affect the risk-return trade-off of the curve momentum strategy.
} 


\section{Main Results}

\subsection{Overview}

Panel A of Table 2 reports the main statistics of the curve momentum strategy excess returns. Throughout this paper, we report the (annualized) mean and volatility of the strategy excess returns. For ease of exposition, we aggregate the results at the sector level. For each commodity sector, we compute the equal-weighted average of the curve momentum strategy excess returns related to each commodity futures market that belongs to that specific sector. For instance, the figure related to the energy sector is obtained by averaging the excess returns on the curve momentum strategy separately implemented in the Brent oil, the WTI oil, the heating oil, and the natural gas futures curves. We do this at the end of each month, thus obtaining the monthly time-series of the sector excess returns. We then use this time-series to compute the summary statistics shown in the table.

Several results are worth noting. First, the curve momentum strategy yields positive average excess returns in all sectors, revealing the profitability of the investment. Second, the Newey-West adjusted (with 2 lags) $t$-statistics indicate that the averages are generally significant. Third, both the mean and the volatility of the curve momentum strategy excess returns are lower than the comparable figures associated with conventional commodity strategies (Fuertes et al., 2010). This result is to be expected. To understand why, recall that there is a strong factor structure in each commodity futures curve. Indeed, the summary statistics shown in Table 1 indicate that the average excess returns and volatilities of the first two nearby series of each market are closely related. Because the strategy takes long and short positions in similar assets in which excess returns are highly correlated (see Table 1), 
the excess returns on the long-short strategy are expected to be small and not very volatile.

Correlation Analysis We now investigate the question of commonalities both within and across sectors. We follow a two-pronged approach to tackle this issue. First, we analyze the correlations within each commodity sector. We compute the correlation between the curve momentum strategy excess returns obtained for all pairs of commodity futures markets that belong to the same sector. We then compute the average of these pairwise correlations, which we view as indicative of the strength of the commonalities within each commodity sector. The main diagonal of Table A.1 of the online appendix reports these results. It becomes apparent that there is very little correlation within sectors. This result is evidenced by correlation estimates that vary between -0.02 (softs) and 0.28 (oilseeds).

Second, we compute the correlation across commodity sectors. Using the time-series of the sector excess returns, we compute the correlation between the curve momentum excess returns of the sector [name in column] and those of the sector [name in row]. The off-diagonal elements of Table A.1 of the online appendix document very small and often negative coefficient estimates, suggesting that there are substantial diversification benefits by combining all sectors.

Diversified Curve Momentum Strategy Motivated by the previous result, we now analyze the performance of the diversified curve momentum strategy computed by taking the equally-weighted average of all sector excess returns. Figure 1 shows the cumulative excess return of the diversified curve momentum strategy. We can see that it generates positive cumulative excess returns. Interestingly, the returns do not crash around the NBER 
recession periods, which are highlighted by the shaded bars. Furthermore, the profitability of the strategy improves during the most recent subsample. This observation has important implications for some of the leading theories of momentum, which we shall discuss later.

The last row of Panel A of Table 2 indicates a positive (1.76\%) and highly significant $(t$-stat $=6.24)$ average excess return on the diversified curve momentum strategy. ${ }^{6,7}$ It is worth noticing that the volatility of the diversified curve momentum excess returns is lower than the comparable figure for most sectors, likely reflecting the benefit of diversification. Relatedly, the diversified curve momentum strategy boasts an annualized $S R$ of 1.28 , that is higher than that of any sector. The skewness (0.14) and kurtosis (3.48) estimates suggest that the performance of the diversified curve momentum strategy is difficult to reconcile with a crash risk argument.

\subsection{Dissecting the Curve Momentum Strategy}

Having documented the profitability of the curve momentum strategy, we now analyze its sources. We proceed in two steps. First, we investigate whether the performance is primarily

\footnotetext{
${ }^{6}$ Table A.2 of the online appendix reports the summary statistics of the excess returns of the $C-M O M$ strategy at the level of each commodity. The table shows that the strategy generally yields positive average excess returns in nearly all commodity markets. Furthermore, the average excess return is statistically significant in 9 of the 22 commodity markets, indicating that the profitability at the asset level contributes to the performance of the diversified $C-M O M$ strategy. Note that the strategy benefits also from a diversification effect, both within and across sectors.

${ }^{7}$ One might wonder if the diversified $C-M O M$ strategy beats a naive spread position that systematically (i) buys the second nearby contract and (ii) shorts the front nearby contract. To shed light on this, we directly implement this naive strategy. Each month, we systematically open a long position in the second-nearest contract and take a short position in the front-end contract of the same commodity futures curve. We first compute the equal-weighted average excess return of this naive strategy across all commodities that make up each sector, thus obtaining the naive spread strategy excess return of each sector. Next, we compute the equal-weighted average across all naive spread sector excess returns to obtain the naive spread diversified strategy. Our untabulated results suggest that this naive diversified spread strategy yields an average excess return of $1.49 \%(t-$ stat $=4.54)$ and an annualized Sharpe ratio of 1.03 . These numbers are lower than those associated with the diversified $C-M O M$ strategy that yields an average excess return of $1.76 \%$ $(t-$ stat $=6.24)$ and an annualized Sharpe Ratio of 1.28. We thank a reviewer for suggesting this analysis.
} 
driven by the long or short sides. Second, we decompose the investment excess returns into static and dynamic components and analyze their respective contributions.

\section{2.a Long vs. Short Legs}

We can express the strategy excess returns as the difference between the weighted excess returns on the assets held (i) on the long side and (ii) on the short side of the trade. Panels B and C of Table 2 present key statistics of the long and short sides, respectively.

The summary statistics for both legs of the trade are generally similar. ${ }^{8}$ This is not surprising given the strong factor structure present in each curve. We note that the volatility of the curve momentum excess returns (see Panel A of Table 2) is much lower than that of either the long or short legs of the trade. This result is another manifestation of the strong factor structure of futures excess returns. Notice also that the average excess returns on the long side of the strategy are generally higher than those of the short side. Consequently, the performance of the curve momentum strategy cannot be explained by arguments based on short-selling constraints.

\section{2.b Static vs. Dynamic Components}

The average excess return $\left(\bar{R}_{C-M O M}^{(m)}\right)$ to the curve momentum strategy implemented in the commodity futures market $m$ is given by:

$$
\bar{R}_{C-M O M}^{(m)}=\sum_{i=1}^{N_{t}^{m}} \mathbb{E}\left(\omega_{C-M O M, t}^{(m, i)} R_{t+1}^{(m, i)}\right)
$$

\footnotetext{
${ }^{8}$ One might note that the excess returns to the long and short sides of the grains and industrials sectors are negative. This observation is consistent with the summary statistics reported in Table 1. See also Table 1 in De Groot et al. (2014).
} 
where $\mathbb{E}(\cdot)$ denotes the unconditional expectation operator. In particular, this expectation is the unconditional mean computed using all sample information.

It follows that:

$$
\begin{aligned}
\bar{R}_{C-M O M}^{(m)} & =\sum_{i=1}^{N_{t}^{m}} \mathbb{E}\left(\omega_{C-M O M, t}^{(m, i)}\right) \mathbb{E}\left(R_{t+1}^{(m, i)}\right)+\sum_{i=1}^{N_{t}^{m}} \operatorname{Cov}\left(\omega_{C-M O M, t}^{(m, i)}, R_{t+1}^{(m, i)}\right) \\
\bar{R}_{C-M O M}^{(m)} & =\underbrace{\sum_{i=1}^{N_{t}^{m}} \mathbb{E}\left(\omega_{C-M O M, t}^{(m, i)}\right) \mathbb{E}\left(R_{t+1}^{(m, i)}\right)}_{\text {Static Component }} \\
& +\underbrace{\sum_{i=1}^{N_{t}^{m}} \mathbb{E}\left(\left(\omega_{C-M O M, t}^{(m, i)}-\mathbb{E}\left(\omega_{C-M O M, t}^{(m, i)}\right)\right)\left(R_{t+1}^{(m, i)}-\mathbb{E}\left(R_{t+1}^{(m, i)}\right)\right)\right)}_{\text {Dynamic Component }}
\end{aligned}
$$

The expression above shows that we can decompose the average excess return on the curve momentum strategy into (i) a static and (ii) a dynamic component. The static component is a passive strategy that simply earns the average excess return on each nearby multiplied by the average weight related to that nearby. ${ }^{9}$ In contrast, the dynamic component can be interpreted as a market timing strategy. ${ }^{10}$

If the strategy always involves a long position in the nearby with the higher unconditional average excess return and a short position in the other nearby, then the static component should capture all the average excess return of the strategy. This is because the weights for each nearby will be constant, making the dynamic component equal to zero. Otherwise, the dynamic component will contribute to the average excess return of the curve momentum

\footnotetext{
${ }^{9}$ The reader may think of the static component of each nearby of each commodity futures market as corresponding to (1) the difference between the fraction of months the strategy involves a long position in that nearby minus the fraction of months during which the strategy involves a short position in that nearby (2) multiplied by the average excess return on that nearby.

${ }^{10}$ Note that this strategy cannot be implemented in real-time since it requires information about the full sample.
} 
strategy. The decomposition presented above allows us to precisely quantify the contribution of these two components to the overall average performance of the strategy.

Panel A of Table 3 establishes that both the static and dynamic components contribute positively to the overall performance of the strategy, as evidenced by positive entries for each of the two components. The dynamic component accounts for $57.75 \%$ of the average excess return to the diversified curve momentum strategy. Panel B of Table 3 shows how often the curve momentum strategy involves a long position in each nearby. We compute the figures for each commodity futures market, then we average these statistics at the sector level and ultimately across sectors. ${ }^{11}$ We observe that the diversified curve momentum strategy takes a long position in the second nearby $66.09 \%$ of the time, indicating that there are time-variations in the weight allocated to each nearby.

\subsection{The Determinants of the Strategy}

We now ask the question: what are the underlying forces behind the performance of the diversified curve momentum strategy? To shed light on this question, we first investigate the extent to which the diversified curve momentum strategy returns reflect a compensation for risk. Next, we consider behavioural theories. While the theories of momentum that we test were originally developed to rationalize the successful performance of the conventional momentum strategy implemented in equity markets, we take the view that, in principle, a unifying theory of momentum should work beyond the confines of a specific asset class.

\footnotetext{
${ }^{11}$ The reader would notice that, by using the entries in Panel B of Table 3 appropriately, one cannot get the estimate of the static component presented in Panel A of Table 3. This may appear contradictory to the intuition developed in Footnote 9. To understand this difference, it is useful to recall that the average of the product of two variables is different from the product of the average of the two variables.
} 


\section{3.a Rational Asset Pricing}

We begin by empirically testing whether rational asset pricing theories can explain the performance of the diversified curve momentum strategy. We consider three main categories of explanatory variables.

The first set of variables relates to the macroeconomy. We compute the monthly growth rate of the U.S. industrial production $(I P)$. This variable is motivated by the theoretical model of Johnson (2002) and the supporting empirical evidence presented in Liu and Zhang (2008). We also consider the default and term spreads (Asness et al., 2013). The default spread $(D S P D)$ is the spread between Moody's seasoned BAA and AAA corporate bond yields. The term spread $(T S P D)$ is the difference between the 10-Year Treasury yield and the 3-Month T-bill yield. We collect all the relevant data from the website of the Federal Reserve Bank of St. Louis.

The second set of explanatory variables relates to liquidity. We construct the TED spread as the difference between the 3-Month T-bill and the 3-Month LIBOR rates. We interpret this measure as a proxy for funding liquidity. ${ }^{12}$ We also consider the role of market liquidity $(L I Q)$, which we proxy with the time-series of innovations in aggregate liquidity (non-traded factor) of Pástor and Stambaugh (2003). We obtain this time-series from the CRSP database. ${ }^{13}$

The final set of explanatory variables relates to the classic risk factors used in the equity

\footnotetext{
${ }^{12}$ Note that the TED spread is typically defined as the difference between the 3-Month LIBOR and T-bill rates. We depart from this definition in order to facilitate the interpretation of the spread as a measure of liquidity.

${ }^{13}$ When we carried out the analysis, this time-series stopped at the end of December 2014. As a result, the analysis focuses on the common sample period that ends in December 2014, rather than February 2015. This small difference of two monthly observations should not materially alter the results.
} 
literature. These are the (US) equity market $(M K T)$, small-minus-big $(S M B)$, high-minuslow $(H M L)$ and up-minus-down $(U M D)$ factors downloaded from Ken French's website. ${ }^{14}$ By using these variables, we are able to shed light on the extent to which the returns on the diversified curve momentum strategy merely reflect passive exposure to standard equity risk factors. Note that the intercept of the regression of the diversified curve momentum strategy excess returns on a constant and the equity risk factor(s) can be validly interpreted as the average risk-adjusted return on the diversified curve momentum strategy. As an additional analysis, we consider the 1-month change in the option implied volatility (VIX) as explanatory variable. ${ }^{15}$

We estimate a regression of the excess returns on the diversified curve momentum strategy on a constant and the explanatory variable(s). All variables are contemporaneously observed. Table 4 summarizes the results. As before, we report the Newey-West corrected $t$-statistics with 2 lags in brackets. The $t$-statistics linked to the slope of the explanatory variables are generally insignificant. For instance, the exposure of the diversified curve momentum strategy to the up-minus-down equity risk factor is 0.01 and the corresponding $t$-statistic is equal to 0.13. In light of this, we conclude that the excess returns on the diversified curve momentum strategy are not significantly exposed to the typical risk variables.

One may wonder whether commodity specific risk factors, rather than equity risk factors, might be able to explain the performance of the diversified curve momentum strategy. Szymanowska et al. (2014) show that two basis factors can explain the cross-section of commodity spreading excess returns sorted by various characteristics. Bakshi et al. (2017) propose a

\footnotetext{
${ }^{14}$ The data is available at the following address (mba.tuck.dartmouth.edu/pages/faculty/ken.french/).

${ }^{15}$ We thank a reviewer for this suggestion.
} 
3-factor pricing model for the cross-section of commodity futures excess returns. The factors are the average commodity factor, the conventional commodity carry, and momentum factors. Boons and Prado (2019) propose the basis momentum and hedged basis momentum factors. Section A of the online appendix describes the computation of the aforementioned commodity risk factors. ${ }^{16}$

We regress the excess returns on the diversified curve momentum strategy on a constant and the commodity risk factors. The low $R^{2} \mathrm{~s}$ in Table 5 show that the commodity risk factors cannot explain the variations in the excess returns on the diversified curve momentum strategy satisfactorily. The average risk-adjusted return is highly significant in every specification. Moreover, its magnitude is comparable to the raw average excess return on the diversified curve momentum strategy reported in Panel A of Table 2. For instance, the intercept in the multivariate regression, that includes the average, the conventional commodity carry, the conventional commodity momentum, the basis momentum and the hedged basis momentum returns as explanatory variables, points to an average risk-adjusted excess return of $1.52 \%(t$-stat $=5.20)$. This is close to the $1.76 \%$ raw average excess return. These findings lead us to conclude that the diversified curve momentum strategy cannot be simply explained by exposure to conventional commodity risk factors.

\section{3.b Behavioral Theories}

We now focus on two leading behavioral explanations of momentum. Daniel et al. (1998) propose a model where informed traders are overconfident about the precision of their private information and exhibit a self-attribution bias. They trade based on the private signal about

\footnotetext{
${ }^{16}$ Table A.3 of the online appendix presents the summary statistics of these risk factors. They are generally consistent with the findings of the literature, e.g. Miffre and Rallis (2007) and Koijen et al. (2018).
} 
the fundamental value of assets. Some investments perform in accordance with the private signal, while others do not. Because of the self-attribution bias, the investments in which performance is consistent with the initial signal boost the overconfidence of the traders and the poor investments only dent their overconfidence. For instance, if the agent receives a positive signal about an asset and its price subsequently increases, the agent becomes more overconfident. As agents become more overconfident, their trading actions raise the price of the assets, thus leading to short-run momentum.

Hong and Stein (1999) present a theory of momentum that features two types of agents, the "newswatchers" and the "momentum traders", both of whom are boundedly rational. Fundamental news diffuses slowly across the "newswatchers". The "newswatchers" exhibit bounded rationality in the sense that they only use the news signal, and do not exploit the information content of historical price trends, to estimate the future value of the asset. The "momentum traders" are boundedly rational in that they only use the historical price changes to estimate the future stock price. Because of the slow diffusion of information, the actions of the "newswatchers" make prices adjust slowly, creating momentum at short horizons. As "momentum traders" observe the trends in asset prices, they start trading in the same direction, strengthening the momentum effect in the short run.

We exploit the passing of the CFMA in December 2000 to empirically distinguish between these two leading theories. As discussed in Boons et al. (2012), the CFMA facilitated the entry of less-sophisticated investors who speculate on commodity futures markets. ${ }^{17}$ This is interesting because, as pointed by Goetzmann and Huang (2018), unsophisticated investors

\footnotetext{
${ }^{17}$ See also the article published by Bloomberg (www.bloomberg.com/news/articles/2008-06-09/oiltraders-face-new-regulationbusinessweek-business-news-stock-market-and-financial-advice).
} 
likely exhibit the overconfidence and self-attribution biases that are essential to the theory of Daniel et al. (1998). If this is true, their model predicts a significantly stronger momentum effect in the more recent sample period. It is also likely that the CFMA substantially increased the speed of information diffusion in commodity futures markets. This effect might arise from the fact that news media outlets increase their coverage of commodity markets in response to the increased demand for commodity news from speculators. ${ }^{18}$ Because the speed of information diffusion is an important ingredient of the theory of Hong and Stein (1999), their model predicts a significantly weaker momentum effect in the period after the CFMA.

The preceding discussion reveals that the two theories have contrasting implications for the performance of the curve momentum strategy during the periods preceding and following the adoption of this important legislation. We therefore split our sample into the "preCFMA" period, which runs from January 1986 to (and including) December 2000, and the "post-CFMA", which extends from January 2001 to February 2015. ${ }^{19}$ We then separately analyze the results related to each subsample.

Table 6 shows that the average excess return to the diversified curve momentum strategy increases from $0.93 \%$ in the pre-CFMA period to $2.58 \%$ in the post-CFMA period. This pattern is qualitatively consistent with the theory of Daniel et al. (1998). We formally test whether this increase in the average excess return of the diversified curve momentum strategy

\footnotetext{
${ }^{18}$ There are potentially other influences on the speed of information diffusion that may not be directly linked to the CFMA. For instance, technological improvements such as newswires may lead to a faster speed of information diffusion. Similarly, the growing popularity of blogs where investors discuss their views could contribute to a faster diffusion of information. In the model of Hong and Stein (1999), these developments could lead to a lower curve momentum return over time.

${ }^{19}$ See Bianchi et al. (2016) and Kim et al. (2016) for recent studies that use the CFMA to motivate their subsample analysis.
} 
across the two subsamples is statistically significant. The $t$-statistic of 3.22 leads us to the conclusion that the average excess return of the diversified strategy is significantly higher in the post-CFMA period. ${ }^{20}$

Summarizing, the empirical results suggest that the performance of the diversified curve momentum strategy is difficult to reconcile with risk-based arguments. Instead, the evidence appears supportive of the model of Daniel et al. (1998).

\section{What About...}

\subsection{Including More Nearbys in the Strategy?}

Our main analysis focuses only on the first 2 nearbys of each market. As previously discussed, this choice was motivated by several considerations, including tradeability concerns and the need to have an easy to implement strategy. However, one may wonder whether our results are robust to the inclusion of more nearbys.

To shed light on this question, we increase the number of nearbys first to 4 and then to 6 . Since the number of nearbys is greater than 3, we also analyze the rank-weighting scheme, putting more weight on contracts based on the strength of the signal. ${ }^{21}$

\footnotetext{
${ }^{20}$ For all but one sector, we observe a higher average curve momentum excess return in the more recent subperiod (compared to the pre-CFMA subsample). This finding is qualitatively consistent with the theory of Daniel et al. (1998). However, the increase in the average excess return of each sector is not always significant.

${ }^{21}$ The weights associated with the rank-weighting scheme are computed as follows:

$$
\omega_{C-M O M, t}^{(m, i)}=z_{t}\left(\operatorname{rank}\left(S_{C-M O M, t}^{(m, i)}\right)-\frac{N_{t}^{m}+1}{2}\right)
$$

where $z_{t}$ is simply a scaling parameter to ensure that the weights on the long and short sides of the strategy add up to 1 and -1 , respectively. $\operatorname{rank}(\cdot)$ is the $\operatorname{rank}$ operator. All other variables are as previously defined. Conceptually, the rank weighting scheme has the advantage that the size of the position in each nearby depends on the magnitude of the trading signal.
} 
Table 7 presents results that are consistent with our core findings. The diversified curve momentum strategy yields a positive and statistically significant average excess return. ${ }^{22}$ Furthermore, the excess returns on the diversified curve momentum are positively skewed, confirming our earlier result. The $S R$ s of these strategies are broadly consistent with our benchmark finding. This is true regardless of the weighting scheme. Thus, we conclude that trading more nearby futures contracts does not materially change our conclusions.

\subsection{Alternative Formation and Holding Periods?}

Up to this point, we have focused on the performance of the diversified $C-\operatorname{MOM}(12,1)$ strategy with a formation period of 12 months and an investment horizon of 1 month. One may wonder whether our findings hold for alternative formation and holding periods. Table 8 considers formation periods of 1, 6 and 12 months and holding periods of 1, 6, 12, 18 and 24 months. ${ }^{23}$

We observe significantly positive average excess returns for all the alternative formation and holding periods. This suggests that the baseline results on the profitability of the diversified curve momentum strategy are robust to the choice of the measurement and holding

\footnotetext{
${ }^{22}$ We also investigate whether the excess returns to the diversified curve momentum strategy computed using more than 2 nearbys in each commodity futures market can be explained by the $B A S M O M$ and $B A S M O M+H$ strategy excess returns. Based on the rank-weighting scheme, we obtain average riskadjusted excess returns of $1.15 \%(t$-stat $=4.76)$ and $1.50 \%(t$-stat $=4.03)$ when using 4 and 6 nearbys, respectively. Similarly, when the analysis is based on the equal-weighting scheme, the average risk adjusted excess returns are equal to $1.35 \%(t$-stat $=5.06)$ and $1.09 \%(t$-stat $=3.59)$ for the strategy considering 4 and 6 nearbys, respectively. We thank a reviewer for this suggestion.

${ }^{23}$ In order to compute long horizon excess returns, we implement the overlapping portfolio approach of Jegadeesh and Titman (1993). Using the weights computed at the end of month $t$, we form a portfolio of nearby contracts that we hold for the next $K$ months, i.e. until the end of month $t+K$. Similarly, at the end of month $t+1$, we (re)compute the trading signal (and weights) and set up a new portfolio that we hold until $t+1+K$. More generally, at the end of each month, we "open" a new portfolio position. The excess return on the strategy at each point in time is the equal-weighted average of the excess returns on all these "open" positions. Intuitively, this is akin to a trading strategy that revises $\frac{1}{K}^{\text {th }}$ of the weights in individual assets at the end of each calendar month (Rouwenhorst, 1998).
} 
periods. Focusing on the investment horizon of 1 month, the diversified $C-\operatorname{MOM}(6,1)$ strategy delivers the highest average excess return $(1.83 \%, t$-stat $=6.91)$. In comparison, the diversified $C-\operatorname{MOM}(12,1)$ and $C-\operatorname{MOM}(1,1)$ strategies yield average excess returns of $1.76 \%(t$-stat $=6.24)$ and $0.93 \%(t$-stat $=3.66)$, respectively. These figures indicate that an investor who measures the trading signal over an intermediate window of 6 months might obtain even better excess returns than those presented in our benchmark analysis.

\subsection{The Samuelson Effect?}

Samuelson (1965) notes that the returns on futures contracts of shorter maturities are typically more volatile than those of longer maturities. If there is a positive risk-return tradeoff that is constant along the term-structure dimension and the term structure of volatility always slopes downward, then the first nearby will display a higher average return than the second nearby. As a result of the Samuelson effect, the curve momentum strategy will always involve long and short positions in the first and second nearbys, respectively.

The line of reasoning above yields several testable hypotheses. First, the term-structure of excess returns slopes downwards. This prediction is not borne out by the data. Indeed, Table 1 and Panel B of Table 3 show that, on average, the term-structure of excess returns slopes upwards rather than downwards. Second, the argument based on the Samuelson (1965) hypothesis counterfactually implies that the strategy always involves a long position in the first nearby and a short position in the second nearby. Panel B of Table 3 shows that the curve momentum strategy often involves a short position in the first nearby and a long position in the second nearby. Third, the average curve momentum excess return arises 
solely from the static component. The data provide no support for this prediction. Indeed, Panel A of Table 3 establishes that the dynamic component contributes to most of the mean excess return of the curve momentum strategy.

Overall, we conclude that the curve momentum strategy is not simply another manifestation of the Samuelson effect. It is, however, interesting to modify the curve momentum strategy to specifically account for the differences in the volatility of the nearby excess returns (see Table 1). To achieve this goal, we first compute the curve momentum trading signal as before (see Section 2.2). We then determine the direction of the position, i.e. long or short, by using the sign of the weight of each nearby). Next, we set the size of the investment in each nearby to be inversely proportional to the historical volatility of the daily excess returns of that nearby. As a result, the monthly excess return on the strategy implemented in a given commodity futures market $m$ is given by the following expression:

$$
R_{C-M O M, t+1}^{(m)}=\sum_{i=1}^{N_{t}^{m}} \operatorname{sign}\left(\omega_{C-M O M, t}^{(m, i)}\right) \frac{40 \% \times R_{t+1}^{(m, i)}}{\sigma_{t}^{(m, i)}}
$$

where $R_{C-M O M, t+1}^{(m)}$ is the curve momentum excess return at the end of month $t+1$ of the strategy implemented in the commodity futures market $m$. $\operatorname{sign}(\cdot)$ is the sign operator. The factor $40 \%$ simply ensures that each position has an ex-ante conditional volatility equal to $40 \%$ per annum (Moskowitz et al., 2012). $\sigma_{t}^{(m, i)}$ is the conditional volatility of the excess returns on the $i^{\text {th }}$ nearby of commodity futures market $m$. We use all daily excess returns observed during the measurement period to compute the annualized historical volatility, which we view as a proxy for the conditional volatility. The decision to use daily (rather than monthly) data is motivated by the work of Andersen et al. (2003), who show that, 
in general, increasing the sampling frequency helps improve the accurate measurement of volatility. All other variables are as previously defined.

Table 9 shows that the (volatility-adjusted) diversified curve momentum strategy yields a similar $S R$ (1.23) to that of the baseline diversified curve momentum strategy $(S R=1.28)$. Thus, we conclude that accounting for differences in volatility does not materially affect our main conclusions.

\subsection{Effects in the Cross-section?}

In the main analysis, we have focused on the time-series of commodity returns. We now also analyze whether $C-M O M$ has explanatory power in the cross-section. ${ }^{24}$ To carry out this empirical analysis, we use the time-series of the (i) first nearby and (ii) spreading returns of each of the 22 commodity markets (see also Boons and Prado (2019)). We use individual commodities rather than portfolios as test assets because individual commodity excess returns are much more difficult to price. For each of the 44 test assets, we first estimate the full sample beta(s) with respect to the risk factor(s). Next, we estimate a regression of the average excess return of each test asset on a constant and the estimated beta(s). We compute the standard errors following Kan et al. (2013).

Panel A of Table 11 of the online appendix starts with the 3-factor model of Bakshi et al. (2017) and gradually adds the basis momentum factor of Boons and Prado (2019) and the diversified $C-M O M$ strategy returns. We find that the market price of risk associated with the latter is not statistically significant. Similarly, Panel B of Table 11 of the online appendix starts with the factor model of Szymanowska et al. (2014) and adds the basis momentum

\footnotetext{
${ }^{24}$ We thank a reviewer for suggesting this analysis.
} 
and the diversified $C-M O M$. We do not find strong evidence to suggest that exposure to $C-M O M$ is priced in the cross-section of our test assets.

\subsection{Decision Delays?}

Up to this point, our analysis assumes that the investor trades as soon as the trading signal is computed. In practice, this may not be feasible, especially for institutional investors where decisions likely need the approval of a committee that does not necessarily meet at the end of each month. As a result, there might be a delay between the time when the signal is measured and the time when the strategy is implemented.

We assess the impact of a decision delay of 1 week on the performance of the diversified curve momentum strategy. To be more specific, we assume that the investor only uses the historical data pertaining to the oldest 11 months and 3 weeks (rather than the full 12 months) of the measurement period to compute the curve momentum signal. At the end of month $t$, the trader then implements the strategy based on the computed trading signal. Thus, there is no overlap between the data used to construct the curve momentum signal and the data used to assess the performance of the strategy. If the decision delay matters, we should notice a significant change in the performance of this modified strategy (relative to the baseline result that does not account for the decision delay).

Table 10 shows that the performance of the modified strategy is generally similar to that of our baseline implementation (see Panel A of Table 2). Looking at the diversified curve momentum strategy, we even notice a slight increase in the mean excess return from $1.76 \%$ to $1.87 \%$ and a decrease in the volatility from $1.38 \%$ to $1.35 \%$. Consequently, the $S R$ rises 
from 1.28 in the baseline case to 1.38 after accounting for the decision delay.

Overall, these findings show that our results are robust to a 1-week decision delay. To some extent, this finding is not surprising because the decision delay represents a small part of the original measurement window of 12 months. It is tempting to speculate on whether a larger decision delay might materially affect our results. We investigate this possibility, by considering a decision delay 3 times bigger, and reach similar conclusions. These results are not tabulated for brevity.

\subsection{Transaction Costs?}

One may wonder whether the profits of the curve momentum strategy are subsumed by transaction costs. ${ }^{25}$ Transaction costs could affect the profitability of the trading strategy through two channels. First, the cost of trading each nearby could be high, thus lowering the net profitability of the strategy. Second, the strategy could involve a high turnover rate.

\section{6.a Estimating Transaction Costs}

Unfortunately, a transaction cost analysis is complicated by the fact that the CRB does not provide information about the bid and ask prices of commodity futures. As a result, we are forced to approximate transaction costs. In order to evaluate the robustness of our results to the modelling assumptions, we consider three distinct specifications.

\footnotetext{
${ }^{25}$ The reader may also wonder about the opportunity cost of putting up margins for the futures contracts. We do not think that margin-related expenses will materially affect our results for two reasons. To begin with, commodity futures embed a certain amount of leverage. As discussed in Footnote 1, a trader typically needs between $3 \%$ and $12 \%$ of the price of the contract as initial margin. Furthermore, because we trade the first two nearby contracts of each commodity futures market, which are very correlated with each other, the margin requirements for this intramarket spread is generally low due to the reduced volatility of the portfolio. For example, the information available on the CME website suggests that, for the WTI crude oil futures contract, the maintenance margin of the intramarket spread represents $10 \%$ of the maintenance margin associated with an outright long position in the first nearby.
} 
First, we build on the work of Locke and Venkatesh (1997), who use the computerized trade reconstruction (CTR) audit trail data from the CME to analyze the cost of commodity futures trading in 1992. The authors document that (round-trip) transaction costs in commodity futures are low, varying between $0.0004 \%$ and $0.033 \%{ }^{26}$ Accordingly, we set the transaction cost $(T C)$ of each nearby to be equal to $0.033 \%$ (Miffre and Rallis, 2007):

$$
T C_{t+1}^{(m, i)}=0.033 \%
$$

where $T C_{t+1}^{(m, i)}$ is the round-trip transaction cost at time $t+1$ associated with the $i^{t h}$ nearby of the commodity futures market $m$.

Second, we follow the modeling framework of Szakmary et al. (2010). The authors note that the bid-ask spread of the first nearby of commodity futures markets generally corresponds to the minimum tick size. Furthermore, they also take into account the brokerage fee, which they set at $\$ 10 .{ }^{27}$ Armed with this information, they propose the following estimator of transaction costs:

$$
T C_{t+1}^{(m, i)}=\frac{10+\operatorname{Tick}^{(m)} \times C M^{(m)}}{F_{t+1}^{(m, i)} \times C M^{(m)}}
$$

where Tick $^{(m)}$ denotes the minimum tick size set by the exchange. $C M^{(m)}$ is the contract multiplier associated with the commodity futures market $m$. The contract multiplier in-

\footnotetext{
${ }^{26}$ The estimates of Locke and Venkatesh (1997) are broadly consistent with those of Ferguson and Mann (2001). More specifically, they report a proportional spread that ranges from 0.59 basis points in the live cattle futures market to 5.56 basis points in the pork belly futures market. On average, the (round-trip) transaction cost documented by the authors across all commodity futures markets is around 2.97 basis points, which is very similar to our assumed cost of 3 basis points (see Equation (6)).

${ }^{27}$ The assumed fee of $\$ 10$ probably overestimates the brokerage fees, at least for the recent sample period. For instance, an online broker such as TradeStation, discussed in Gao et al. (2018), charges around $\$ 1.5$ per commodity futures contract.
} 
dicates the number of units of the underlying commodity deliverable per futures contract. Table 1 lists the contract multiplier and tick size of each commodity futures. All other variables are as previously defined.

The model summarized in Equation (7) allows for time-variations in the trading cost associated with each futures market. Note, however, that the assumption of a flat termstructure of bid-ask spreads needs not imply a static term-structure of transaction costs. If the term-structure of commodity futures markets is in contango, i.e. the term-structure of commodity futures prices slopes upwards, then the term-structure of transaction costs will slope downwards. Conversely, a backwardated term-structure of futures contracts would result in an upward sloping term-structure of rates.

Third, we propose a model of transaction cost that extends the framework of Szakmary et al. (2010) by allowing for the impact of the tick size on the transaction cost estimate to be higher for deferred contracts. ${ }^{28}$ To be more specific, we propose the following model:

$$
T C_{t+1}^{(m, i)}=\frac{10+i \times T i c k^{(m)} \times C M^{(m)}}{F_{t+1}^{(m, i)} \times C M^{(m)}}
$$

where all variables are as previously defined.

\footnotetext{
${ }^{28}$ Analyzing a snapshot of the Bloomberg estimates of the bid-ask spread for the first two nearby contracts in January 2016, we observe that the bid-ask spread is the same for the first two nearby contracts of virtually all commodity futures markets. Thus, the assumption that the bid-ask spread increases linearly with $i$ is somewhat at odds with that piece of evidence. One way to think about this assumption is as a simple way to capture other effects, such as the fact that the trading volume on the first nearby is generally higher than that of the second nearby.
} 


\section{6.b Turnover Rate}

The turnover rate may be affected by two forces. To begin with, it may be due to the fact that changes in the trading signal could lead to an adjustment of the positions linked to each nearby. We refer to this channel as the rebalancing effect. In addition to that effect, the turnover rate may arise from the fact that commodity futures expire and thus, positions need to be rolled over.

We compute the turnover rate induced by rebalancing effects for each nearby contract of each commodity futures market as follows:

$$
T U R N_{R e b a l, t+1}^{(m, i)}=\left|\omega_{C-M O M, t}^{(m, i)}-\tilde{\omega}_{C-M O M,(t-1)^{+}}^{(m, i)}\right|
$$

where $T U R N_{\text {Rebal,t+1 }}^{(m, i)}$ denotes the turnover rate, induced by rebalancing effects, at time $t+1$ associated with the $i^{t h}$ nearby of the commodity futures market $m . \tilde{\omega}_{C-M O M,(t-1)^{+}}^{(m, i)}$ is the weight in that nearby just before setting up the new position.

$$
\tilde{\omega}_{C-M O M,(t-1)^{+}}^{(m, i)}=\frac{\omega_{C-M O M, t-2}^{(m, i)}\left(1+R_{t-1}^{(m, i)}\right)}{\sum_{i=1}^{N_{t}^{m}} \omega_{C-M O M, t-2}^{(m, i)}\left(1+R_{t-1}^{(m, i)}\right)}
$$

In accounting for both the rebalancing and the rollover effects, it is useful to distinguish between two situations. First, there is no rollover effect. In this case, the turnover rate corresponds exactly to that induced by the rebalancing channel (see Equation (9)). Second, there is a rollover. In this case, the turnover is based on the difference between the weight 
in the new $i^{\text {th }}$ nearby and that of the $i+1^{\text {th }}$ nearby just before the rollover.

$$
T U R N_{\text {Rebal\&Roll }, t+1}^{(m, i)}= \begin{cases}\left|\omega_{C-M O M, t}^{(m, i)}-\tilde{\omega}_{C-M O M,(t-1)^{+}}^{(m, i)}\right| & \text { If There is no Rollover } \\ \left|\omega_{C-M O M, t}^{(m, i)}-\tilde{\omega}_{C-M O M,(t-1)^{+}}^{(m, i+1)}\right| & \text { Otherwise }\end{cases}
$$

\section{6.c Transaction Costs and Turnover Estimates.}

Figure 2 shows the time-series of the transaction cost estimates for the first nearby (blue line) and the second nearby (red line). We obtain the (aggregate) transaction cost estimate at each point in time by first averaging the estimates at the sector level and then across all sectors. The top and bottom panels are based on the transaction cost models in Equations (7) and (8). We can see time-variations in the transaction cost estimates. Interestingly, transaction costs have fallen in the more recent sample. The declining pattern is consistent with the works of Tang and Xiong (2012) and Cheng and Xiong (2014), among others, who document an increase in commodity trading activity shortly after the CFMA. An upshot of this visual cue is that, if the curve momentum strategy were costly to implement, improvements in trading conditions would have lowered the magnitude of the strategy return (Chordia et al., 2014) as more arbitrageurs pile into the trade. The visual evidence of Figure 1 paints a different picture: the diversified curve momentum strategy performs even better during the more recent period. This pattern seems difficult to reconcile with a limits-toarbitrage argument.

Table 11 sheds light on the turnover rate of the curve momentum strategy. We first average the turnover rate across all nearby contracts of each commodity futures market. Next, we average these estimates within each sector and then across sectors, yielding the 
figures for the diversified curve momentum strategy. Intuitively, we expect the rebalancing effect to be small because the trading signal is based on the past 12 months of data, making it somewhat persistent. The entries under "Rebal" confirm this intuition. On average, the diversified strategy involves a low turnover rate of $19.24 \%$ per contract. The turnover rises from $19.24 \%$ per contract to $125.62 \%$ when we account also for the rollover effects. ${ }^{29}$ It appears important to carefully account for rollover effects when computing the net returns on the curve momentum strategy.

\section{6.d Net Excess Returns}

Table 12 analyzes the net excess returns on the curve momentum strategy. We compute the net excess return related to a given month by subtracting the transaction cost estimate of that month from the raw excess return obtained for that month:

$$
\tilde{R}_{C-M O M, t+1}^{(m)}=R_{C-M O M, t+1}^{(m)}-0.5 \times \sum_{i=1}^{N_{t}^{m}} T U R N_{\text {Rebal\&Roll }, t+1}^{(m, i)} \times T C_{t+1}^{(m, i)}
$$

where $\tilde{R}_{C-M O M, t+1}^{(m)}$ is the net excess return on the curve momentum strategy implemented in commodity futures market $m$. All remaining variables are as previously defined. Note that we multiply the transaction cost estimates by 0.5 because the estimates of trading costs relate to a round-trip cost. ${ }^{30}$

\footnotetext{
${ }^{29}$ The reader may notice that the results for the energy sector are even more striking as evidenced by the rise from $17.63 \%$ when accounting only for the rebalancing effect to $190.80 \%$ when accounting for both rebalancing and rollover effects. This result arises because energy derivatives have a monthly expiration cycle, inducing frequent rollovers.

${ }^{30}$ The analysis could be criticized on the ground that, for a one-way trade, the investor would pay the full brokerage fee rather than half of it. We repeat the analysis using each of the following equations to approximate the one-way transaction cost:

$$
T C_{\text {one-way,t+1 }}^{(m, i)}=\frac{10+0.5 \times \text { Tick }^{(m)} \times C M^{(m)}}{F_{t+1}^{(m, i)} \times C M^{(m)}}
$$


Overall, the average net excess return on the diversified strategy is about $30 \%$ lower than the raw average excess return. Yet, the Sharpe ratio, after accounting for transaction costs, remains sizable, ranging from 0.85 to 0.93 (depending on the model for transaction costs). We thus conclude that transaction costs do not subsume the excess returns of the curve momentum strategy returns. ${ }^{31}$

\section{Conclusion}

This paper proposes the curve momentum strategy that operates within each futures curve, trading different nearby contracts written on the same commodity. The average excess return to the diversified curve momentum strategy is significantly positive. Moreover, we find that the average excess return is significantly higher in the more recent sample period.

The curve momentum profits do not appear to compensate for risk. Indeed, neither a multi-factor model that includes the conventional commodity carry, the conventional commodity momentum, the basis momentum and the hedged basis momentum strategy returns nor other known risk factors can explain the diversified curve momentum strategy excess re-

$$
T C_{\text {one-way }, t+1}^{(m, i)}=\frac{10+0.5 i \times T i c k^{(m)} \times C M^{(m)}}{F_{t+1}^{(m, i)} \times C M^{(m)}}
$$

The net excess return is then obtained as:

$$
\tilde{R}_{C-M O M, t+1}^{(m)}=R_{C-M O M, t+1}^{(m)}-\sum_{i=1}^{N_{t}^{m}} T U R N_{\text {Rebal\& Roll }, t+1}^{(m, i)} \times T C_{\text {one-way }, t+1}^{(m, i)}
$$

Although the average excess return is a bit lower than the estimates in Table 12, the key conclusions are qualitatively similar. We do not tabulate these findings for brevity.

${ }^{31}$ It is, however, important to acknowledge that transaction costs have a significant impact on the results for some sectors. Consistent with its high turnover rate, the profitability of the average curve momentum strategy in the energy sector is subsumed by transaction costs. While Panel A of Table 2 shows that the average excess return to the strategy is $1.10 \%$, accounting for transaction costs reduces this return to $-0.35 \%$ (Panel B of Table 12). 
turns satisfactorily. Furthermore, transaction costs cannot explain why the diversified curve momentum profits persist. 


\section{References}

Andersen, T. G., Bollerslev, T., Diebold, F. X., and Labys, P. (2003). Modeling and forecasting realized volatility. Econometrica, 71(2):579-625.

Ang, A., Shtauber, A. A., and Tetlock, P. C. (2013). Asset pricing in the dark: The crosssection of OTC stocks. Review of Financial Studies, 26(12):2985-3028.

Arismendi, J. C., Back, J., Prokopczuk, M., Paschke, R., and Rudolf, M. (2016). Seasonal stochastic volatility: Implications for the pricing of commodity options. Journal of Banking E Finance, 66:53-65.

Asness, C. S., Moskowitz, T. J., and Pedersen, L. H. (2013). Value and momentum everywhere. Journal of Finance, 68(3):929-985

Back, J., Prokopczuk, M., and Rudolf, M. (2013). Seasonality and the valuation of commodity options. Journal of Banking \& Finance, 37(2):273-290.

Bakshi, G., Gao, X., and Rossi, A. G. (2017). Understanding the sources of risk underlying the cross-section of commodity returns. Management Science, 65(2):619-641.

Bianchi, R. J., Drew, M. E., and Fan, J. H. (2016). Commodities momentum: A behavioral perspective. Journal of Banking \& Finance, 72:133-150.

Boons, M., de Roon, F., and Szymanowska, M. (2012). The stock market price of commodity risk. AFA Meetings Paper.

Boons, M. and Prado, M. P. (2019). Basis-momentum. Journal of Finance, 74(1):239-279. 
Cheng, H. and Xiong, W. (2014). Financialization of commodity markets. Annual Review of Financial Economics, 6:419-41.

Chordia, T., Subrahmanyam, A., and Tong, Q. (2014). Have capital market anomalies attenuated in the recent era of high liquidity and trading activity? Journal of Accounting and Economics, 58(1):41-58.

Chui, A. C., Titman, S., and Wei, K. J. (2003). Intra-industry momentum: The case of REITs. Journal of Financial Markets, 6(3):363-387.

Daniel, K., Hirshleifer, D., and Subrahmanyam, A. (1998). Investor psychology and security market under- and overreactions. Journal of Finance, 53(6):1839-1885.

De Groot, W., Karstanje, D., and Zhou, W. (2014). Exploiting commodity momentum along the futures curves. Journal of Banking 8 Finance, 48:79-93.

Diewald, L., Prokopczuk, M., and Wese Simen, C. (2015). Time-variations in commodity price jumps. Journal of Empirical Finance, 31:72-84.

Erb, C. B. and Harvey, C. R. (2006). The strategic and tactical value of commodity futures. Financial Analysts Journal, 62(2):69-97.

Ferguson, M. F. and Mann, S. C. (2001). Execution costs and their intraday variation in futures markets. Journal of Business, 74(1):125-160.

Fuertes, A.-M., Miffre, J., and Rallis, G. (2010). Tactical allocation in commodity futures markets: Combining momentum and term structure signals. Journal of Banking \& Finance, 34(10):2530-2548. 
Gao, L., Han, Y., Li, S. Z., and Zhou, G. (2018). Market intraday momentum. Journal of Financial Economics, 129(2):394-414.

Goetzmann, W. N. and Huang, S. (2018). Momentum in imperial Russia. Journal of Financial Economics, 130(3):579-591.

Gorton, G. B., Hayashi, F., and Rouwenhorst, K. G. (2013). The fundamentals of commodity futures returns. Review of Finance, 17(1):35-105.

Hedegaard, E. (2014). Causes and consequences of margin levels in futures markets. Working Paper.

Hong, H. and Stein, J. C. (1999). A unified theory of underreaction, momentum trading, and overreaction in asset markets. Journal of Finance, 54(6):2143-2184.

Jegadeesh, N. and Titman, S. (1993). Returns to buying winners and selling losers: Implications for stock market efficiency. Journal of Finance, 48(1):65-91.

Johnson, T. C. (2002). Rational momentum effects. Journal of Finance, 57(2):585-608.

Kan, R., Robotti, C., and Shanken, J. (2013). Pricing model performance and the two-pass cross-sectional regression methodology. Journal of Finance, 68(6):2617-2649.

Kim, A. Y., Tse, Y., and Wald, J. K. (2016). Time series momentum and volatility scaling. Journal of Financial Markets, 30:103-124.

Koijen, R. S., Moskowitz, T. J., Pedersen, L. H., and Vrugt, E. B. (2018). Carry. Journal of Financial Economics, 127(2):197-225. 
Liu, L. X. and Zhang, L. (2008). Momentum profits, factor pricing, and macroeconomic risk. Review of Financial Studies, 21(6):2417-2448.

Locke, P. R. and Venkatesh, P. (1997). Futures market transaction costs. Journal of Futures Markets, 17(2):229-245.

Miffre, J. and Rallis, G. (2007). Momentum strategies in commodity futures markets. Journal of Banking \& Finance, 31(6):1863-1886.

Moskowitz, T. J., Ooi, Y. H., and Pedersen, L. H. (2012). Time series momentum. Journal of Financial Economics, 104(2):228-250.

Pástor, L. and Stambaugh, R. F. (2003). Liquidity risk and expected stock returns. Journal of Political Economy, 111(3):642-685.

Rouwenhorst, K. G. (1998). International momentum strategies. Journal of Finance, $53(1): 267-284$.

Samuelson, P. A. (1965). Proof that properly anticipated prices fluctuate randomly. Industrial Management Review, 6(2):41-49.

Singleton, K. J. (2014). Investor flows and the 2008 boom/bust in oil prices. Management Science, 60(2):300-318.

Szakmary, A. C., Shen, Q., and Sharma, S. C. (2010). Trend-following trading strategies in commodity futures: A re-examination. Journal of Banking ES Finance, 34(2):409-426.

Szymanowska, M., Roon, F., Nijman, T., and Goorbergh, R. (2014). An anatomy of commodity futures risk premia. Journal of Finance, 69(1):453-482. 
Tang, K. and Xiong, W. (2012). Index investment and the financialization of commodities. Financial Analysts Journal, 68(5):54-74. 


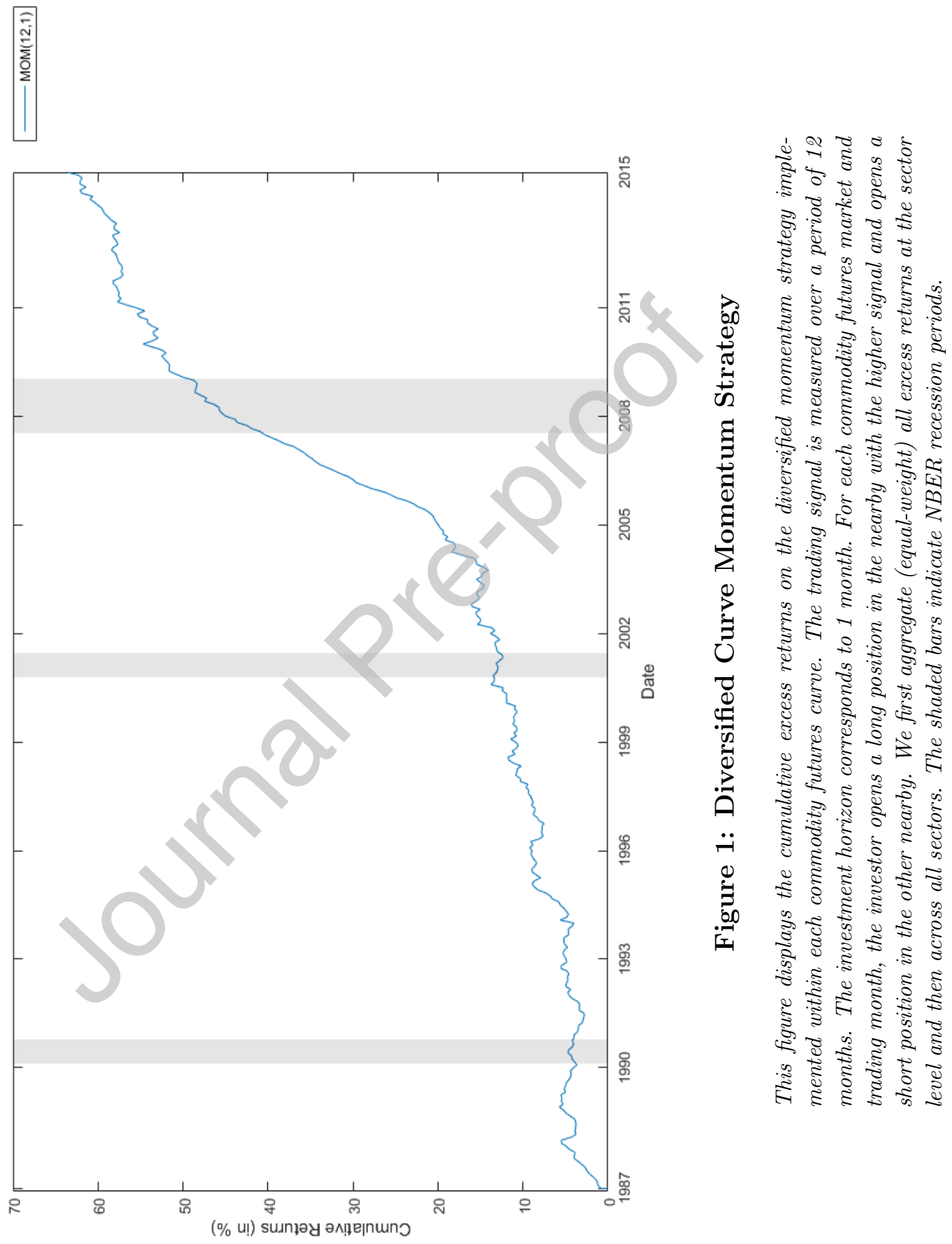




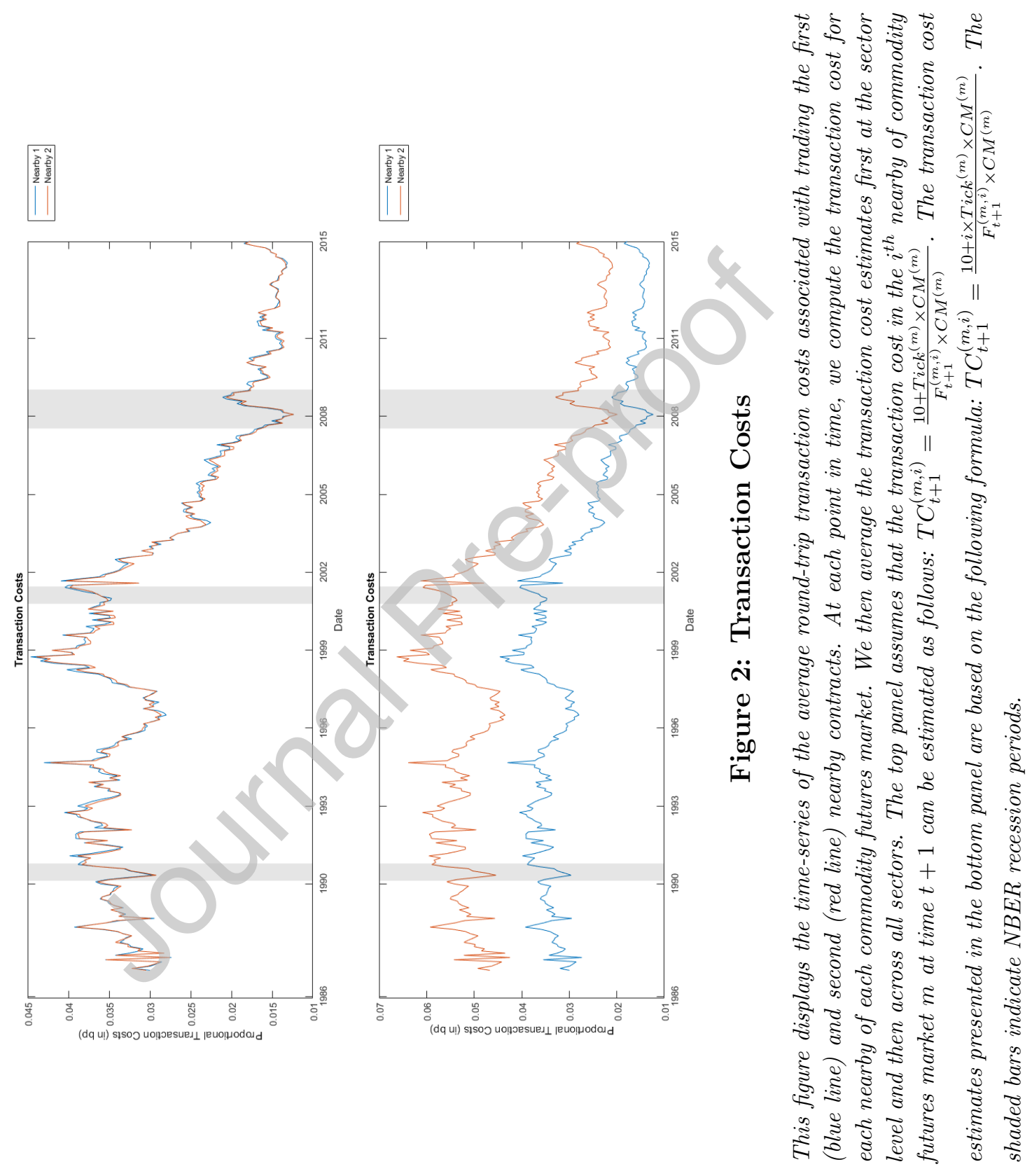




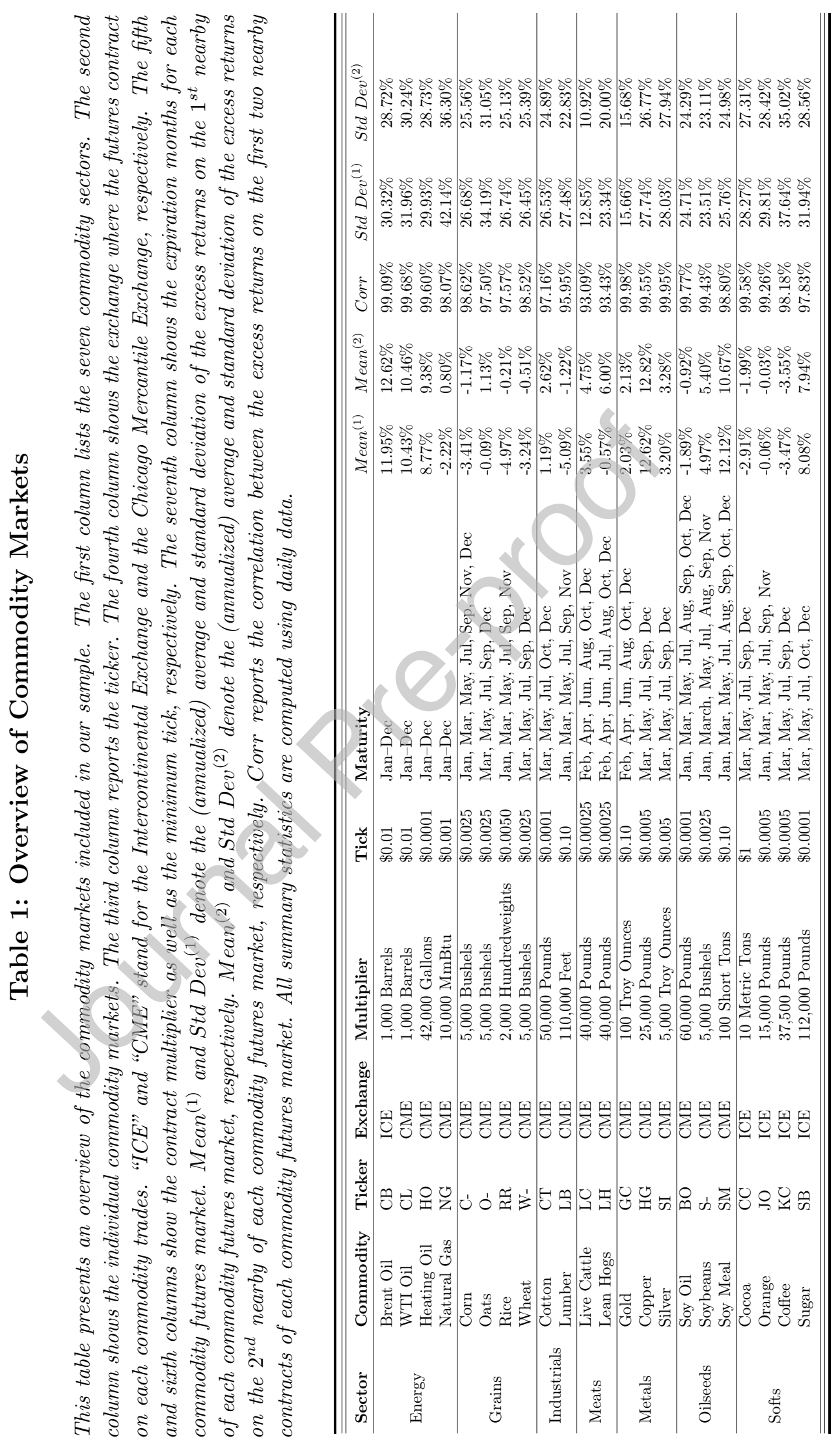


This table presents the summary statistics of the returns on the curve momentum strategy. The trading signal is measured over a period of 12 months. The investment horizon corresponds to 1 month. For each commodity futures market and trading month, the investor opens a long position in the nearby contract with the higher signal and opens a short position in the other nearby. We aggregate and report all excess returns at the sector level. The last row presents the results for the diversified portfolio computed as the equal-weighted average of the strategy excess returns obtained at the sector level. Panel A focuses on the Long-Short strategy. We separately present the results for the long (Panel B) and short (Panel C) legs of the strategy. "Mean" reports the (annualized) average excess return of the strategy. " $t$-stat" is the Newey-West corrected (with 2 lags) test statistic associated with the mean excess return. "Std Dev" denotes the (annualized) standard deviation of the excess returns. "Skew" and "Kurt" are the skewness and kurtosis, respectively. "JB" is the Jarque-Bera $p$-value of the test that the excess returns are normally distributed. Finally, "SR" is the (annualized) Sharpe ratio.

Panel A: Long-Short Strategy

\begin{tabular}{lccccccc}
\hline \hline & Mean & $t$-stat & Std Dev & Skew & Kurt & JB & SR \\
\hline Energy & $1.10 \%$ & $(2.08)$ & $3.03 \%$ & 0.55 & 17.24 & $0.10 \%$ & 0.36 \\
Grains & $2.37 \%$ & $(3.87)$ & $3.03 \%$ & -0.05 & 6.09 & $0.10 \%$ & 0.78 \\
Industrial Materials & $2.62 \%$ & $(2.58)$ & $5.12 \%$ & -0.14 & 4.42 & $0.10 \%$ & 0.51 \\
Meats & $5.07 \%$ & $(4.88)$ & $5.11 \%$ & 0.31 & 5.85 & $0.10 \%$ & 0.99 \\
Metals & $0.12 \%$ & $(0.66)$ & $0.93 \%$ & -0.20 & 17.91 & $0.10 \%$ & 0.13 \\
Oilseeds & $0.76 \%$ & $(2.18)$ & $2.11 \%$ & 0.27 & 11.66 & $0.10 \%$ & 0.36 \\
Softs & $0.28 \%$ & $(0.61)$ & $2.71 \%$ & 0.33 & 20.01 & $0.10 \%$ & 0.10 \\
Diversified & $1.76 \%$ & $(6.24)$ & $1.38 \%$ & 0.14 & 3.48 & $9.15 \%$ & 1.28 \\
\hline \hline
\end{tabular}

Panel B: Long Leg

\begin{tabular}{lccccccc}
\hline \hline & Mean & $t$-stat & Std Dev & Skew & Kurt & JB & SR \\
\hline Energy & $9.70 \%$ & $(1.67)$ & $27.07 \%$ & 0.44 & 5.53 & $0.10 \%$ & 0.36 \\
Grains & $-0.25 \%$ & $(-0.06)$ & $20.59 \%$ & 0.65 & 6.95 & $0.10 \%$ & -0.01 \\
Industrial Materials & $-0.65 \%$ & $(-0.17)$ & $19.18 \%$ & 0.12 & 4.05 & $0.35 \%$ & -0.03 \\
Meats & $5.68 \%$ & $(2.02)$ & $13.93 \%$ & -0.24 & 3.13 & $15.26 \%$ & 0.41 \\
Metals & $6.38 \%$ & $(1.90)$ & $18.55 \%$ & -0.25 & 5.50 & $0.10 \%$ & 0.34 \\
Oilseeds & $6.31 \%$ & $(1.50)$ & $22.28 \%$ & 0.05 & 4.00 & $0.51 \%$ & 0.28 \\
Softs & $1.32 \%$ & $(0.38)$ & $17.70 \%$ & -0.02 & 3.29 & $50.00 \%$ & 0.07 \\
Diversified & $4.07 \%$ & $(1.72)$ & $11.61 \%$ & -0.45 & 6.46 & $0.10 \%$ & 0.35 \\
\hline \hline
\end{tabular}

Panel C: Short Leg

\begin{tabular}{lccccccc}
\hline \hline & Mean & $t$-stat & Std Dev & Skew & Kurt & JB & SR \\
\hline Energy & $8.59 \%$ & $(1.47)$ & $27.66 \%$ & 0.45 & 5.50 & $0.10 \%$ & 0.31 \\
Grains & $-2.62 \%$ & $(-0.64)$ & $21.02 \%$ & 0.77 & 8.21 & $0.10 \%$ & -0.12 \\
Industrial Materials & $-3.27 \%$ & $(-0.84)$ & $19.56 \%$ & 0.07 & 3.49 & $13.31 \%$ & -0.17 \\
Meats & $0.61 \%$ & $(0.21)$ & $14.47 \%$ & -0.22 & 3.04 & $22.85 \%$ & 0.04 \\
Metals & $6.25 \%$ & $(1.86)$ & $18.48 \%$ & -0.26 & 5.47 & $0.10 \%$ & 0.34 \\
Oilseeds & $5.55 \%$ & $(1.32)$ & $22.42 \%$ & -0.01 & 4.08 & $0.34 \%$ & 0.25 \\
Softs & $1.03 \%$ & $(0.30)$ & $18.05 \%$ & 0.00 & 3.38 & $33.08 \%$ & 0.06 \\
Diversified & $2.31 \%$ & $(0.98)$ & $11.75 \%$ & -0.49 & 6.61 & $0.10 \%$ & 0.20 \\
\hline \hline
\end{tabular}




\section{Table 3: Static vs. Dynamic Components}

This table decomposes the excess returns on the curve momentum strategy into static and dynamic components. The trading signal is measured over a period of 12 months. The investment horizon corresponds to 1 month. For each commodity futures market and trading month, the investor opens a long position in the nearby contract with the higher signal and opens a short position in the other nearby. We aggregate and report all excess returns at the sector level. The last row presents the results for the diversified portfolio computed as the equal-weighted average of sector excess returns. We decompose the average excess return to the curve momentum strategy into its static and dynamic components. Panel A sheds light on the contribution of each component. "Total" reports the annualized average excess return to the curve momentum strategy. "Static" shows the annualized average excess return linked to the static component, whereas "Dynamic" shows the annualized average excess return due to the dynamic component. "\% Share (Dynamic)" reports the proportion of the total curve momentum excess return that is due to the average of the dynamic component. We compute this as the average excess return to the dynamic component divided by the average total excess return to the strategy. Panel B shows how often the strategy involves a long or short position in each nearby. Long ${ }^{(1)}$ and Short ${ }^{(1)}$ report how often the strategy entails a long and short position in the first nearby, respectively. $\bar{R}^{(1)}$ is the average excess return on the first nearby. Long ${ }^{(2)}$ and Short ${ }^{(2)}$ indicate how often the investor opens a long and short position the second nearby, respectively. $\bar{R}^{(2)}$ is the average excess return on the second nearby.

Panel A: Decomposition

\begin{tabular}{lcccc}
\hline \hline & \multicolumn{3}{c}{ Returns } & \\
\cline { 2 - 4 } & Total & Static & Dynamic & \% Share (Dynamic) \\
\hline Energy & $1.10 \%$ & $0.28 \%$ & $0.83 \%$ & $74.85 \%$ \\
Grains & $2.37 \%$ & $1.81 \%$ & $0.55 \%$ & $23.42 \%$ \\
Industrials & $2.62 \%$ & $1.07 \%$ & $1.55 \%$ & $59.16 \%$ \\
Meats & $5.07 \%$ & $1.60 \%$ & $3.46 \%$ & $68.38 \%$ \\
Metals & $0.12 \%$ & $0.05 \%$ & $0.07 \%$ & $58.66 \%$ \\
Oilseeds & $0.76 \%$ & $0.27 \%$ & $0.49 \%$ & $63.91 \%$ \\
Softs & $0.28 \%$ & $0.12 \%$ & $0.16 \%$ & $58.12 \%$ \\
Diversified & $1.76 \%$ & $0.74 \%$ & $1.02 \%$ & $57.75 \%$ \\
\hline \hline
\end{tabular}

\section{Panel B: Frequency}

\begin{tabular}{|c|c|c|c|c|c|c|}
\hline & $\operatorname{Long}^{(1)}$ & Short $^{(1)}$ & $\bar{R}^{(1)}$ & $\operatorname{Long}^{(2)}$ & Short $^{(2)}$ & $\bar{R}^{(2)}$ \\
\hline Energy & $34.12 \%$ & $65.88 \%$ & $7.86 \%$ & $65.88 \%$ & $34.12 \%$ & $8.83 \%$ \\
\hline Grains & $21.93 \%$ & $78.07 \%$ & $-2.55 \%$ & $78.07 \%$ & $21.93 \%$ & $0.28 \%$ \\
\hline Industrials & $34.02 \%$ & $65.98 \%$ & $-3.62 \%$ & $65.98 \%$ & $34.02 \%$ & $-0.30 \%$ \\
\hline Meats & $37.61 \%$ & $62.39 \%$ & $0.77 \%$ & $62.39 \%$ & $37.61 \%$ & $5.01 \%$ \\
\hline Metals & $37.57 \%$ & $62.43 \%$ & $6.22 \%$ & $62.43 \%$ & $37.57 \%$ & $6.41 \%$ \\
\hline Oilseeds & $38.76 \%$ & $61.24 \%$ & $5.94 \%$ & $61.24 \%$ & $38.76 \%$ & $5.93 \%$ \\
\hline Softs & $33.36 \%$ & $66.64 \%$ & $1.07 \%$ & $66.64 \%$ & $33.36 \%$ & $1.28 \%$ \\
\hline Diversified & $33.91 \%$ & $66.09 \%$ & $2.24 \%$ & $66.09 \%$ & $33.91 \%$ & $3.92 \%$ \\
\hline
\end{tabular}




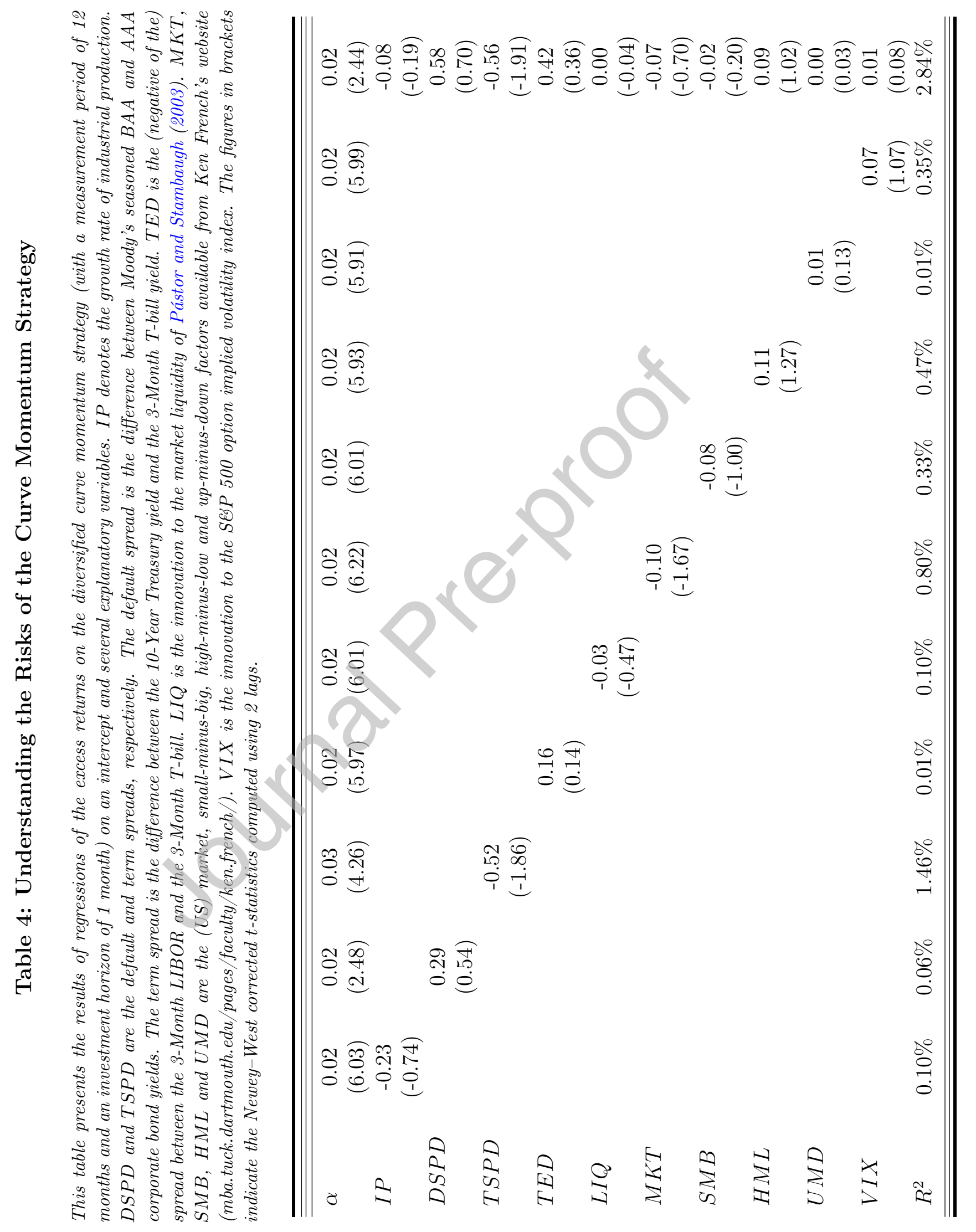




\section{Table 5: Commodity Risk Factors and the Diversified Curve Momentum}

This table analyzes the relationship between the diversified curve momentum strategy and various commodity risk factors. $R_{X S-M O M}$ is the excess return on the cross-sectional momentum strategy. $R_{X S-C R Y}$ is the excess return of the cross-sectional carry strategy. $R_{A V G}$ is the excess return to the average strategy that involves a long position in the first nearby of each commodity market. $R_{B A S M O M}$ is the excess return on the basis momentum strategy. $R_{B A S M O M+H}$ is the excess return to the hedged basis momentum strategy. $R_{S P R E A D}^{(H M L)}$ is the spreading excess return on the long-short basis strategy. $R_{S P R E A D}^{(L N G)}$ and $R_{S P R E A D}^{(S H T)}$ are the spreading excess returns on the long and short legs of the basis strategy of Szymanowska et al. (2014), respectively. All strategies have a 1 month investment horizon. Panel A is mainly focused on the risk factors of Bakshi et al. (2017), while Panel B focuses on those of Szymanowska et al. (2014). The figures in brackets indicate the Newey-West corrected t-ratio computed using 2 lags.

Panel A: Bakshi et al. (2017)

\begin{tabular}{|c|c|c|c|c|c|c|}
\hline$\alpha$ & $\begin{array}{l}0.016 \\
(5.728)\end{array}$ & $\begin{array}{c}0.017 \\
(5.779)\end{array}$ & $\begin{array}{c}0.018 \\
(6.321)\end{array}$ & $\begin{array}{c}0.016 \\
(5.316)\end{array}$ & $\begin{array}{c}0.016 \\
(5.394)\end{array}$ & $\begin{array}{l}0.015 \\
(5.199)\end{array}$ \\
\hline$R_{X S-M O M}$ & $\begin{array}{c}0.012 \\
(2.329)\end{array}$ & & & & & $\begin{array}{c}0.009 \\
(1.049)\end{array}$ \\
\hline$R_{X S-C R Y}$ & & $\begin{array}{c}0.010 \\
(1.622)\end{array}$ & & & & $\begin{array}{c}0.000 \\
(0.039)\end{array}$ \\
\hline$R_{A V G}$ & & & & & & $\begin{array}{c}-0.014 \\
(-2.662)\end{array}$ \\
\hline$R_{B A S M O M}$ & & & & $\begin{array}{l}0.014 \\
(2.262)\end{array}$ & & $\begin{array}{c}0.000 \\
(0.006)\end{array}$ \\
\hline$R_{B A S M O M+H}$ & & & & & $\begin{array}{c}0.122 \\
(3.996)\end{array}$ & $\begin{array}{c}0.105 \\
(3.048)\end{array}$ \\
\hline$R^{2}$ & $2.41 \%$ & $1.26 \%$ & $1.30 \%$ & $1.87 \%$ & $5.61 \%$ & $8.00 \%$ \\
\hline
\end{tabular}

Panel B: Szymanowska et al. (2014)

\begin{tabular}{|c|c|c|c|c|c|c|}
\hline$\alpha$ & $\begin{array}{c}0.017 \\
(5.949)\end{array}$ & $\begin{array}{c}0.017 \\
(6.337)\end{array}$ & $\begin{array}{c}0.018 \\
(6.127)\end{array}$ & $\begin{array}{c}0.016 \\
(5.416)\end{array}$ & $\begin{array}{c}0.016 \\
(5.472)\end{array}$ & $\begin{array}{c}0.016 \\
(5.571)\end{array}$ \\
\hline$R_{S P R E A D}^{(H M L)}$ & $\begin{array}{l}0.110 \\
(3.456)\end{array}$ & & & & & \\
\hline$R_{S P R E A D}^{(L N G)}$ & & $\begin{array}{c}0.201 \\
(4.204)\end{array}$ & & & & $\begin{array}{c}0.158 \\
(3.176)\end{array}$ \\
\hline$R_{S P R E A D}^{(S H T)}$ & & & $\begin{array}{l}-0.039 \\
(-0.990)\end{array}$ & & & $\begin{array}{c}0.002 \\
(0.057)\end{array}$ \\
\hline$R_{B A S M O M}$ & & & & $\begin{array}{l}0.014 \\
(2.262)\end{array}$ & & $\begin{array}{c}0.001 \\
(0.194)\end{array}$ \\
\hline$R_{B A S M O M+H}$ & & & & & $\begin{array}{c}0.122 \\
(3.996)\end{array}$ & $\begin{array}{l}0.085 \\
(2.311)\end{array}$ \\
\hline$R^{2}$ & $4.69 \%$ & $6.77 \%$ & $0.34 \%$ & $1.87 \%$ & $5.61 \%$ & $9.36 \%$ \\
\hline
\end{tabular}




\section{Table 6: Subsample Analysis}

This table presents summary statistics of the excess returns on the curve momentum strategy. The trading signal is measured over a period of 12 months. The investment horizon corresponds to 1 month. For each commodity futures market and trading month, the investor opens a long position in the nearby contract with the higher signal and opens a short position in the other nearby. We aggregate and report all excess returns at the sector level. The last row presents the results for the diversified portfolio computed as the equal-weighted average of the curve momentum strategy excess returns obtained at the sector level. We split the sample into two periods centered around the adoption of the Commodity Futures Modernisation Act (CFMA) in December 2000. We separately present the results for the period up to (and including) December 2000 (Pre-CFMA) and after December 2000 (Post-CFMA). "Difference" reports the difference between the average Post-CFMA excess return and the average Pre-CFMA excess return. "Mean" reports the annualized average excess return. "t-stat" shows the t-ratio associated with the figured reported under "Mean". We use the Newey-West corrected (with 2 lags) standard errors to compute these test statistics.

\begin{tabular}{l|ll|ll|ll}
\hline \hline \multirow{2}{*}{ Sector } & \multicolumn{2}{|c}{ Pre-CFMA } & \multicolumn{2}{c|}{ Post-CFMA } & \multicolumn{2}{c}{ Difference } \\
\cline { 2 - 7 } & Mean & t-stat & Mean & $t$-stat & Mean & $t$-stat \\
\hline Energy & $0.69 \%$ & $(0.73)$ & $1.52 \%$ & $(2.40)$ & $0.83 \%$ & $(0.72)$ \\
Grains & $1.60 \%$ & $(2.14)$ & $3.12 \%$ & $(3.28)$ & $1.52 \%$ & $(1.33)$ \\
Industrials & $0.56 \%$ & $(0.41)$ & $4.64 \%$ & $(3.21)$ & $4.08 \%$ & $(2.13)$ \\
Meats & $2.37 \%$ & $(1.77)$ & $7.73 \%$ & $(5.13)$ & $5.36 \%$ & $(2.81)$ \\
Metals & $0.00 \%$ & $(0.01)$ & $0.24 \%$ & $(2.12)$ & $0.24 \%$ & $(0.67)$ \\
Oilseeds & $0.63 \%$ & $(1.72)$ & $0.89 \%$ & $(1.50)$ & $0.27 \%$ & $(0.34)$ \\
Softs & $0.65 \%$ & $(0.92)$ & $-0.08 \%$ & $(-0.14)$ & $-0.74 \%$ & $(-0.72)$ \\
Diversified & $0.93 \%$ & $(2.59)$ & $2.58 \%$ & $(6.31)$ & $1.65 \%$ & $(3.22)$ \\
\hline \hline
\end{tabular}




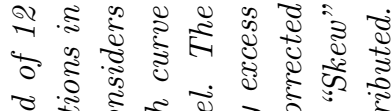

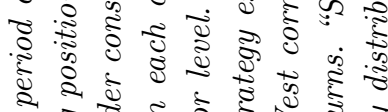

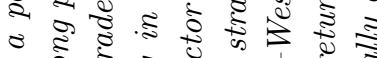

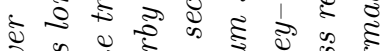
ปे ช

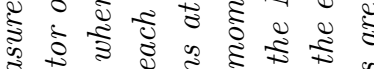

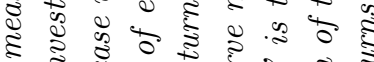

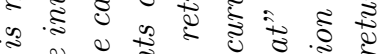

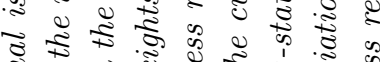

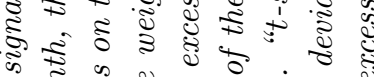
के हु व. कू

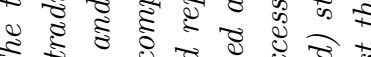

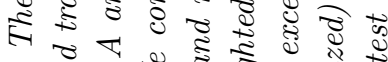

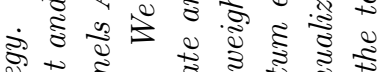
वे

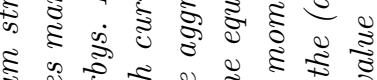

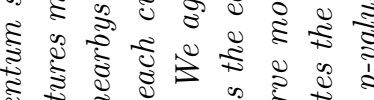

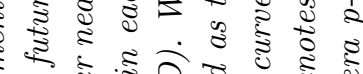
ำ

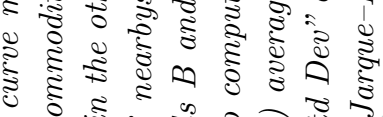
वृ. है ๘

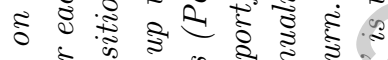
है ते

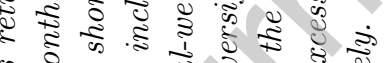

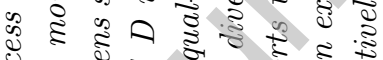
ㄱำ

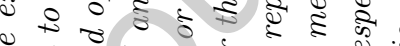
ॠ

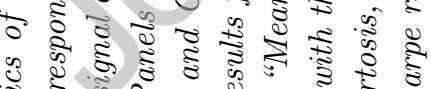
4 कर

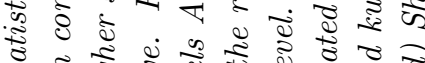

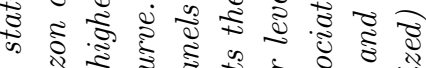

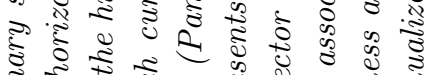
हैं

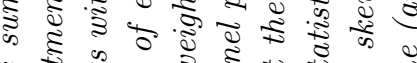

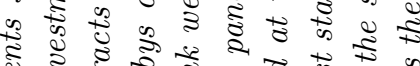

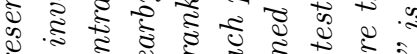

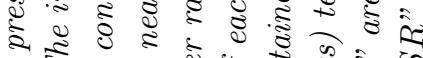

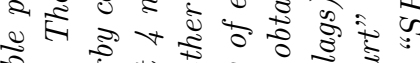

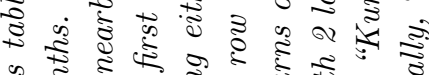

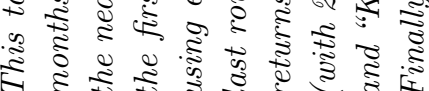

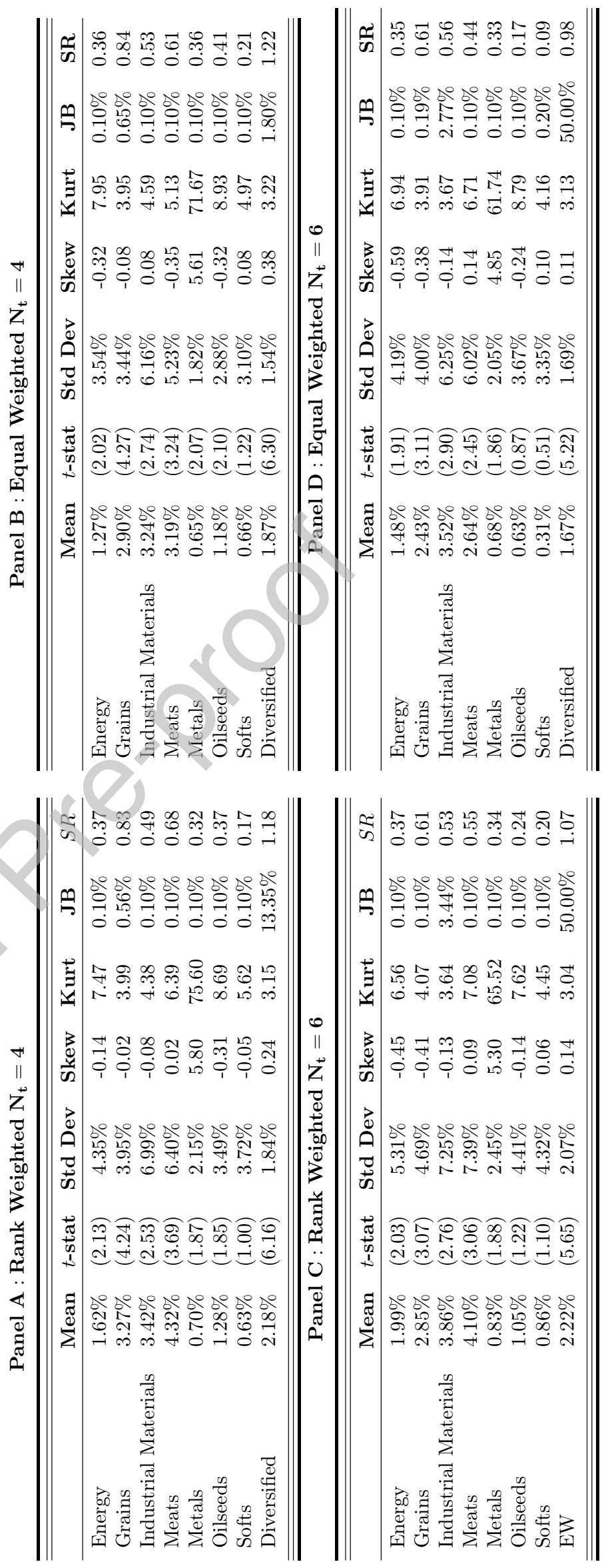




\section{Table 8: Alternative Formation and Holding Periods}

This table presents summary statistics of the diversified curve momentum strategy implemented within each commodity futures curve. The trading signal is measured over a period of $J$ months. The investment horizon corresponds to $K$ months. For each commodity futures market and trading month, the investor opens a long position in the nearby contract with the higher signal and opens a short position in the other nearby. We report the results of the diversified curve momentum strategy computed by first aggregating all excess returns at the sector level and then taking an equal-weighted average of sector excess returns. We present the (annualized) average excess return of the diversified curve momentum strategy. The figures in parentheses indicate the Newey-West $t$-statistics computed with $K+1$ lags. The numbers in square brackets show the (annualized) Sharpe ratio of the related strategy.

\begin{tabular}{cccccc}
\hline \hline $\mathbf{J} / \mathbf{K}$ & $\mathbf{1}$ & $\mathbf{6}$ & $\mathbf{1 2}$ & $\mathbf{1 8}$ & $\mathbf{2 4}$ \\
\hline \multirow{3}{*}{1} & $0.93 \%$ & $0.99 \%$ & $1.03 \%$ & $0.87 \%$ & $0.86 \%$ \\
& $(3.66)$ & $(5.16)$ & $(4.37)$ & $(3.15)$ & $(2.90)$ \\
& {$[0.68]$} & {$[1.49]$} & {$[1.75]$} & {$[1.59]$} & {$[1.66]$} \\
\multirow{3}{*}{6} & $1.83 \%$ & $1.65 \%$ & $1.49 \%$ & $1.33 \%$ & $1.30 \%$ \\
& $(6.91)$ & $(5.36)$ & $(3.91)$ & $(3.16)$ & $(2.90)$ \\
& {$[1.40]$} & {$[1.56]$} & {$[1.56]$} & {$[1.51]$} & {$[1.57]$} \\
\multirow{3}{*}{12} & $1.76 \%$ & $1.49 \%$ & $1.28 \%$ & $1.23 \%$ & $1.24 \%$ \\
& $(6.24)$ & $(4.17)$ & $(3.02)$ & $(2.75)$ & $(2.64)$ \\
& {$[1.28]$} & {$[1.24]$} & {$[1.13]$} & {$[1.18]$} & {$[1.27]$} \\
\hline \hline
\end{tabular}




\section{Table 9: Excess Returns on the Curve Momentum Strategy: The Samuelson Effect}

This table presents summary statistics of the modified curve momentum strategy that measures the momentum signal over a period of 12 months. The holding period of the strategy is 1 month. The modified strategy accounts for the difference in the volatility of the returns of the two nearbys. For each commodity futures market and trading month, the investor opens a long position in the nearby contract with the higher signal and opens a short position in the other nearby. The size of the investment in each nearby is inversely proportional to the volatility of its excess returns measured over the past 12 months. We aggregate all strategy excess returns at the sector level and also report the results for the diversified portfolio computed as the equal-weighted average of sector excess returns. "Mean" reports the (annualized) average curve momentum excess return. "t-stat" is the Newey-West corrected (with 2 lags) test statistic associated with the mean excess return. "Std Dev" denotes the (annualized) standard deviation of the excess returns. "Skew" and "Kurt" are the skewness and kurtosis, respectively. "JB" is the Jarque-Bera p-value of the test that the excess returns are normally distributed. Finally, "SR" is the (annualized) Sharpe ratio.

\begin{tabular}{lccccccc}
\hline \hline & Mean & t-stat & Std Dev & Skew & Kurt & JB & SR \\
\hline Energy & $1.05 \%$ & $(1.73)$ & $3.25 \%$ & 0.26 & 17.32 & $0.10 \%$ & 0.32 \\
Grains & $3.93 \%$ & $(3.85)$ & $4.94 \%$ & 0.23 & 4.97 & $0.10 \%$ & 0.80 \\
Industrial Materials & $2.08 \%$ & $(1.33)$ & $7.78 \%$ & 0.06 & 4.68 & $0.10 \%$ & 0.27 \\
Meats & $12.25 \%$ & $(5.00)$ & $11.42 \%$ & 0.13 & 3.75 & $1.86 \%$ & 1.07 \\
Metals & $0.14 \%$ & $(0.58)$ & $1.25 \%$ & 0.29 & 10.37 & $0.10 \%$ & 0.11 \\
Oilseeds & $1.31 \%$ & $(2.14)$ & $3.50 \%$ & 0.18 & 8.01 & $0.10 \%$ & 0.37 \\
Softs & $0.23 \%$ & $(0.36)$ & $3.33 \%$ & 0.02 & 7.77 & $0.10 \%$ & 0.07 \\
Diversified & $3.00 \%$ & $(5.51)$ & $2.43 \%$ & -0.03 & 3.00 & $50.00 \%$ & 1.23 \\
\hline \hline
\end{tabular}




\section{Table 10: Decision Delay}

This table presents summary statistics of the excess returns on the curve momentum strategy. We assume the investor uses the oldest 11 months and 3 weeks of data (of the past 12 months) to compute the trading signal. The investment horizon corresponds to 1 month. For each commodity futures market and trading month, the investor opens a long position in the nearby contract with the higher signal and opens a short position in the other nearby. We aggregate and report all excess returns at the sector level. The last row presents the results for the diversified portfolio computed as the equal-weighted average of the strategy excess returns obtained for individual sectors. "Mean" reports the (annualized) average curve momentum excess return. " $t$-stat" is the Newey-West corrected (with 2 lags) test statistic associated with the mean excess return. "Std Dev" denotes the (annualized) standard deviation of the excess returns. "Skew" and "Kurt" are the skewness and kurtosis, respectively. "JB" is the Jarque-Bera p-value of the test that the excess returns are normally distributed. Finally, "SR" is the (annualized) Sharpe ratio.

\begin{tabular}{lccccccc}
\hline \hline & Mean & t-stat & Std Dev & Skew & Kurt & JB & SR \\
\hline Energy & $0.99 \%$ & $(1.90)$ & $3.00 \%$ & 0.71 & 17.65 & $0.10 \%$ & 0.33 \\
Grains & $2.71 \%$ & $(4.47)$ & $3.01 \%$ & -0.05 & 6.27 & $0.10 \%$ & 0.90 \\
Industrial Materials & $2.64 \%$ & $(2.57)$ & $5.18 \%$ & -0.14 & 4.37 & $0.10 \%$ & 0.51 \\
Meats & $5.29 \%$ & $(5.26)$ & $5.08 \%$ & 0.26 & 6.01 & $0.10 \%$ & 1.04 \\
Metals & $0.11 \%$ & $(0.71)$ & $0.94 \%$ & 0.21 & 17.77 & $0.10 \%$ & 0.12 \\
Oilseeds & $0.64 \%$ & $(1.79)$ & $2.04 \%$ & 0.35 & 12.87 & $0.10 \%$ & 0.31 \\
Softs & $0.73 \%$ & $(1.23)$ & $2.79 \%$ & 2.51 & 23.71 & $0.10 \%$ & 0.26 \\
Diversified & $1.87 \%$ & $(6.67)$ & $1.35 \%$ & 0.09 & 3.35 & $30.82 \%$ & 1.38 \\
\hline \hline
\end{tabular}




\section{Table 11: Transaction Cost: Breakdown}

This table sheds light on the transaction costs associated with the $C-\operatorname{MOM}(12,1)$ strategy. In order to compute the (round-trip) transaction costs (TC), we use three distinct assumptions. Panel A assumes constant transaction costs of $0.033 \%$ in each nearby contract. Panel B models the transaction cost in each nearby as a function of the brokerage fee, the futures price, the bid-ask spread which corresponds to 1 tick size and the contract multiplier. Panel $C$ presents the results when the bid-ask spread component is allowed to be different for different nearbys. "TC ${ }^{(1)}$ " and " $T C^{(2)}$ " report the average round-trip transaction costs in the first and second nearby contract, respectively. "Rebal" shows the turnover rate (per nearby) induced by the rebalancing effect. "Rebal \& Roll" shows the turnover rate (per nearby) due to (1) rebalancing and (2) rollover effects.

Panel A: $T C_{t+1}^{(m, i)}=0.03 \%$

\begin{tabular}{lcccc}
\hline \hline & $T C^{(1)}$ & $T C^{(2)}$ & Rebal & Rebal \& Roll \\
\hline Energy & $0.033 \%$ & $0.033 \%$ & $17.63 \%$ & $190.80 \%$ \\
Grains & $0.033 \%$ & $0.033 \%$ & $17.68 \%$ & $94.43 \%$ \\
Industrials & $0.033 \%$ & $0.033 \%$ & $22.19 \%$ & $97.04 \%$ \\
Meats & $0.033 \%$ & $0.033 \%$ & $13.02 \%$ & $116.86 \%$ \\
Metals & $0.033 \%$ & $0.033 \%$ & $21.01 \%$ & $158.68 \%$ \\
Oilseeds & $0.033 \%$ & $0.033 \%$ & $20.81 \%$ & $127.71 \%$ \\
Softs & $0.033 \%$ & $0.033 \%$ & $22.34 \%$ & $93.79 \%$ \\
Diversified & $0.033 \%$ & $0.033 \%$ & $19.24 \%$ & $125.62 \%$ \\
\hline \hline
\end{tabular}

Panel B: $T C_{t+1}^{(m, i)}=\frac{10+T i c k^{(m)} \times C M^{(m)}}{F_{t+1}^{(m, i)} \times C M^{(m)}}$

\begin{tabular}{lcccc}
\hline \hline & TC & & Rebal & Rebal \& Roll \\
\hline Energy & $0.063 \%$ & $0.063 \%$ & $17.63 \%$ & $190.80 \%$ \\
Grains & $0.031 \%$ & $0.030 \%$ & $17.68 \%$ & $94.43 \%$ \\
Industrials & $0.019 \%$ & $0.019 \%$ & $22.19 \%$ & $97.04 \%$ \\
Meats & $0.001 \%$ & $0.001 \%$ & $13.02 \%$ & $116.86 \%$ \\
Metals & $0.015 \%$ & $0.015 \%$ & $21.01 \%$ & $158.68 \%$ \\
Oilseeds & $0.032 \%$ & $0.033 \%$ & $20.81 \%$ & $127.71 \%$ \\
Softs & $0.035 \%$ & $0.034 \%$ & $22.34 \%$ & $93.79 \%$ \\
Diversified & $0.028 \%$ & $0.028 \%$ & $19.24 \%$ & $125.62 \%$ \\
\hline \hline
\end{tabular}

Panel C: $T C_{t+1}^{(m, i)}=\frac{10+i \times T i c k(m) \times C M^{(m)}}{F_{t+1}^{(m, i)} \times C M^{(m)}}$

\begin{tabular}{lcccc}
\hline \hline & $T C^{(1)}$ & $T C^{(2)}$ & Rebal & Rebal \& Roll \\
\hline Energy & $0.063 \%$ & $0.092 \%$ & $17.63 \%$ & $190.80 \%$ \\
Grains & $0.031 \%$ & $0.045 \%$ & $17.68 \%$ & $94.43 \%$ \\
Industrials & $0.019 \%$ & $0.038 \%$ & $22.19 \%$ & $97.04 \%$ \\
Meats & $0.001 \%$ & $0.001 \%$ & $13.02 \%$ & $116.86 \%$ \\
Metals & $0.015 \%$ & $0.023 \%$ & $21.01 \%$ & $158.68 \%$ \\
Oilseeds & $0.032 \%$ & $0.049 \%$ & $20.81 \%$ & $127.71 \%$ \\
Softs & $0.035 \%$ & $0.051 \%$ & $22.34 \%$ & $93.79 \%$ \\
Diversified & $0.028 \%$ & $0.043 \%$ & $19.24 \%$ & $125.62 \%$ \\
\hline \hline
\end{tabular}


This table presents summary statistics of the net excess returns on the $C-\operatorname{MOM}(12,1)$ strategy. In order to compute the round-trip transaction costs, we use three distinct assumptions. Panel A assumes constant transaction costs of $0.033 \%$ in each nearby contract. Panel B models the transaction cost in each nearby as a function of the brokerage fee, the futures price, the bid-ask spread that corresponds to 1 tick size and the contract multiplier. Panel $C$ presents the results when the bid-ask spread component is allowed to be different for different nearbys. "Mean" reports the (annualized) average excess return of the strategy. " $t$-stat" is the Newey-West corrected (with 2 lags) test statistic associated with the mean excess return. "Std Dev" denotes the (annualized) standard deviation of the excess returns. "Skew" and "Kurt" are the skewness and kurtosis, respectively. "JB" is the Jarque-Bera p-value of the test that the excess returns are normally distributed. Finally, "SR" is the (annualized) Sharpe ratio.

Panel A: $T C_{t+1}^{(m, i)}=0.03 \%$

\begin{tabular}{lccccccc}
\hline \hline & Mean & $t$-stat & Std Dev & Skew & Kurt & JB & SR \\
\hline Energy & $0.34 \%$ & $(0.64)$ & $3.03 \%$ & 0.55 & 17.26 & $0.10 \%$ & 0.11 \\
Grains & $1.99 \%$ & $(3.25)$ & $3.03 \%$ & -0.05 & 6.13 & $0.10 \%$ & 0.66 \\
Industrial Materials & $2.23 \%$ & $(2.20)$ & $5.11 \%$ & -0.14 & 4.42 & $0.10 \%$ & 0.44 \\
Meats & $4.60 \%$ & $(4.42)$ & $5.13 \%$ & 0.32 & 5.87 & $0.10 \%$ & 0.90 \\
Metals & $-0.51 \%$ & $(-2.80)$ & $0.94 \%$ & -0.16 & 17.91 & $0.10 \%$ & -0.55 \\
Oilseeds & $0.25 \%$ & $(0.71)$ & $2.12 \%$ & 0.24 & 11.57 & $0.10 \%$ & 0.12 \\
Softs & $-0.09 \%$ & $(-0.20)$ & $2.71 \%$ & 0.34 & 19.81 & $0.10 \%$ & -0.03 \\
Diversified & $1.26 \%$ & $(4.46)$ & $1.38 \%$ & 0.13 & 3.48 & $9.89 \%$ & 0.91 \\
\hline \hline
\end{tabular}

Panel B: $T C_{t+1}^{(m, i)}=\frac{10+T i c k(m) \times C M^{(m)}}{F_{t+1}^{(m, i)} \times C M^{(m)}}$

\begin{tabular}{lccccccc}
\hline \hline & Mean & $t$-stat & Std Dev & Skew & Kurt & JB & SR \\
\hline \hline Energy & $-0.35 \%$ & $(-0.64)$ & $3.05 \%$ & 0.49 & 16.97 & $0.10 \%$ & -0.11 \\
Grains & $1.98 \%$ & $(3.22)$ & $3.04 \%$ & -0.04 & 6.06 & $0.10 \%$ & 0.65 \\
Industrial Materials & $2.38 \%$ & $(2.35)$ & $5.11 \%$ & -0.13 & 4.41 & $0.10 \%$ & 0.46 \\
Meats & $5.06 \%$ & $(4.87)$ & $5.11 \%$ & 0.31 & 5.85 & $0.10 \%$ & 0.99 \\
Metals & $-0.14 \%$ & $(-0.77)$ & $0.93 \%$ & -0.21 & 17.85 & $0.10 \%$ & -0.15 \\
Oilseeds & $0.24 \%$ & $(0.71)$ & $2.11 \%$ & 0.26 & 11.52 & $0.10 \%$ & 0.12 \\
Softs & $-0.10 \%$ & $(-0.22)$ & $2.71 \%$ & 0.32 & 19.67 & $0.10 \%$ & -0.04 \\
Diversified & $1.29 \%$ & $(4.51)$ & $1.39 \%$ & 0.12 & 3.42 & $15.50 \%$ & 0.93 \\
\hline \hline
\end{tabular}

Panel C: $T C_{t+1}^{(m, i)}=\frac{10+i \times T i c k(m) \times C M^{(m)}}{F_{t+1}^{(m, i)} \times C M^{(m)}}$

\begin{tabular}{lccccccc}
\hline \hline & Mean & $t$-stat & Std Dev & Skew & Kurt & JB & SR \\
\hline Energy & $-0.70 \%$ & $(-1.27)$ & $3.06 \%$ & 0.47 & 16.86 & $0.10 \%$ & -0.23 \\
Grains & $1.88 \%$ & $(3.06)$ & $3.04 \%$ & -0.04 & 6.05 & $0.10 \%$ & 0.62 \\
Industrial Materials & $2.25 \%$ & $(2.22)$ & $5.11 \%$ & -0.13 & 4.41 & $0.10 \%$ & 0.44 \\
Meats & $5.05 \%$ & $(4.87)$ & $5.11 \%$ & 0.31 & 5.85 & $0.10 \%$ & 0.99 \\
Metals & $-0.19 \%$ & $(-1.05)$ & $0.93 \%$ & -0.22 & 17.79 & $0.10 \%$ & -0.21 \\
Oilseeds & $0.11 \%$ & $(0.32)$ & $2.11 \%$ & 0.26 & 11.47 & $0.10 \%$ & 0.05 \\
Softs & $-0.20 \%$ & $(-0.43)$ & $2.71 \%$ & 0.31 & 19.55 & $0.10 \%$ & -0.07 \\
Diversified & $1.17 \%$ & $(4.06)$ & $1.39 \%$ & 0.12 & 3.41 & $17.64 \%$ & 0.85 \\
\hline \hline
\end{tabular}

